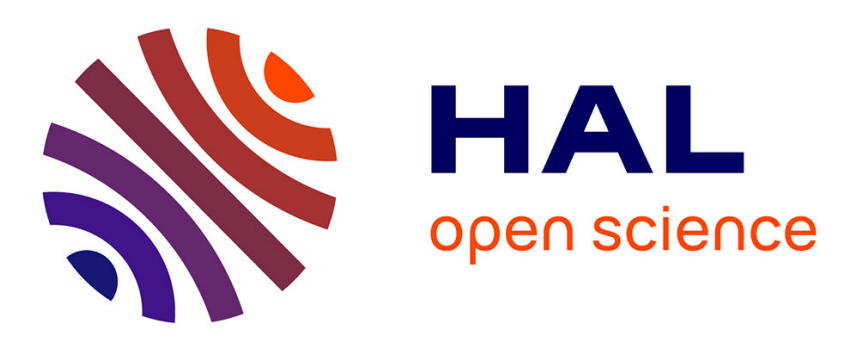

\title{
Numerical and Theoretical Evaluations of a Full-Scale Compartment Fire with an Externally Venting Flame
} Mathieu Duny, Dhionis Dhima, Jean-Pierre Garo, Hui-Ying Wang

\section{To cite this version:}

Mathieu Duny, Dhionis Dhima, Jean-Pierre Garo, Hui-Ying Wang. Numerical and Theoretical Evaluations of a Full-Scale Compartment Fire with an Externally Venting Flame. Fire Technology, 2019, 55 (6), pp.2087-2113. 10.1007/s10694-019-00845-5 . hal-02353270

\section{HAL Id: hal-02353270 \\ https://hal.science/hal-02353270}

Submitted on 23 Nov 2020

HAL is a multi-disciplinary open access archive for the deposit and dissemination of scientific research documents, whether they are published or not. The documents may come from teaching and research institutions in France or abroad, or from public or private research centers.
L'archive ouverte pluridisciplinaire HAL, est destinée au dépôt et à la diffusion de documents scientifiques de niveau recherche, publiés ou non, émanant des établissements d'enseignement et de recherche français ou étrangers, des laboratoires publics ou privés. 
Numerical and theoretical evaluations of a full-scale compartment fire with an externally venting flame

\author{
Mathieu DUNY², Dhionis DHIMA ${ }^{1}$, Jean-Pierre GARO ${ }^{2}$, Hui-Ying WANG ${ }^{2}$ \\ wang@ensma.fr
}

${ }^{1}$ Centre Scientifique et Technique du Bâtiment, 84 avenue Jean Jaurès, Champs sur Marne, 77447 Marne-La-Vallée Cedex 2, France

2 Institut P', Fluides-Thermique-Combustion, CNRS, ENSMA, Université de Poitiers, BP 40109, 86961 Futuroscope Chasseneuil Cedex, France

\begin{abstract}
Understanding of the physics and mechanisms of externally venting flames from enclosure fires with parallel sidewalls at the opening is fundamental to investigating fire spread of U-shape building façade. This work aims to identify the impact of separation distance of sidewalls on façade flame height, heat flux and sustained internal combustion. A series of numerical simulations is conducted in a full-scale compartment with $3.6 \mathrm{~m}$ in length/width and $3.1 \mathrm{~m}$ in height. An external façade wall is measured $6 \mathrm{~m}$ in height and $3.6 \mathrm{~m}$ in width. A pyrolysis surface with an area of $3.2 \times 3.2 \mathrm{~m}^{2}$ is placed in the middle of the enclosure with a theoretical heat lease rate varying from 1 to $8 \mathrm{MW}$. The semi-empirical correlations, derived from a cubic enclosure of $0.4 \mathrm{~m}$ with a HRR lower than $250 \mathrm{~kW}$, are evaluated for a full scale façade fire for identifying the flame height dependence on the separation distance of sidewalls. It is found that an enhanced buoyancy-induced flow between sidewalls leads to an increase of the flame height by a factor of $50 \%$ and a rise of the peak of radiation heat flux by a factor of $20 \%$ as compared to a flat façade fire. The height of externally venting flame is sensitively reduced by a factor of $40-50 \%$ with an increase of the normalized sidewalls distance by opening width up to 3 . The predicted flame height is more pronounced with an increase of flame height by a factor of $40 \%$ for a full scale façade than for a small scale one due to turbulence development. The predicted internal HRR is in quantitative agreement with the one from the correlation for a Global Equivalence Ratio (GER) below 3. The predicted temperatures are in good agreement with the experimental data except in the intermittent-like regions where an over-prediction of the temperature by a factor of $50 \%$ is found due to a reduction in accuracy of LES combustion model.
\end{abstract}

Keywords: compartment fire, externally venting flame, heat flux, façade, parallel sidewalls, opening

\title{
1. INTRODUCTION
}


As an important fundamental topic in fire and combustion research, compartment fire phenomena have been studied for decades. The ventilated compartment fires have always occupied a large proportion of the research effort in fire science. The works [1-3] verified theoretically and experimentally that the heat release rate depends on the amount of air consumed inside the compartment, which is proportional to the ventilation factor. Recent publications [4-7] using numerical simulations for the well ventilated enclosure fire are specially focused on studying qualitatively the thermal behaviour [4], visibility [5] and pressure [6]. Sikanen et al. [7] performed fully predictive simulations of liquid pool fires in mechanically ventilated compartments in a full-scale room. The quantitative agreement is fair with an overprediction of the burning rate of liquid fuel [7].

When a fire inside a compartment develops to be at its most vigorous stage, flames may spill out of openings, forming externally venting flames, also known as façade fires. The structural barrier (for example, balconies) affects significantly the vertical spread of opening spill plume [8-10]. Numerical investigations show that for a compartment fire, opening geometry [11] and prevailing ventilation conditions $[12,13]$ severely impact the interior fire behaviour via oxygen availability and the development of externally venting flame. In the work of Asimakopoulou et al. [14], an overall qualitative assessment of the correlations [15-17] is presented as compared to measurements obtained in large-scale façade fire tests. It is found that the correlations [15] originating from the experimental investigation of fire plumes significantly under-predict the external venting flame temperature and heat flux near the opening. The correlations [16] exhibit a more conservative behaviour with a significant over-prediction of the temperature along a large-scale façade fire. Predictions of the heat flux to the façade, using various correlations [17], highlighted the sensibility to the empirical extinction coefficient. Effects of façade inclination $[18,19]$ on ventilated façade and their thermal behavior have been also a topic of research over the last years. Tang et al. [18] studied the opening ejected façade flame characteristics with air entrainment constraint by a sloping wall. It is found that the façade flame height and the heat flux increased with an increase in sloping wall angle. Quinn et al. [19] performed an experimental investigation of localized fire on façade with different inclination. It was observed that the inclined façade had a faster initial growth rate in terms of both heat flux and temperature for a similar heat release rate. The effects of external wind on the ejected flame along the façade wall from a compartment with multiple openings was also investigated [20, 21]. Lu et al. [20] described experimentally the merging behavior of flames ejected from two parallel openings of an under-ventilated compartment fire. Their results show that the flame height decreases as the separation distance between openings increases, and reaches the value corresponding to a single opening as the separation distance is beyond a critical value. The propagation of ejected externally venting flame is strongly accelerated due to the external wind from an opposing opening [21].

Limit work $[1,2]$ has been conducted to describe the effects of the presence of sidewalls adjacent to an opening on the ventilation factor, and consequently, the propagation of ejected externally venting flame. A real ejected fire propagation [14] from the openings of the vertical U-shape building façade to the upper floors is shown in Fig.1. A buoyancy-induced flow between sidewalls significantly increase radiation and convection of the flames associated 
directly to the ejected spill flame height. The semi-empirical correlations [1, 2] are commonly derived in conjunction with experimental data from a reduce-scale enclosure with sidewalls. All these experiments were performed using a heat release rate (HRR) lower than $250 \mathrm{~kW}$. The correlations derived from large scale test are not available for the effects of sidewalls on the flame height and heat flux. In the current study, a real case of U-shape building façade fire (cf. Fig.1) is simplified as a full-scale compartment fire with an externally venting flame between two vertical parallel walls, as schematized in Figure 2. Quantitative comparisons were first made between several computational results and well-instrumented experimental databases from a full-scale enclosure fire scenario, allowing to identify the strengths and weaknesses of the version 6.2 of FDS [22]. A wide variety of possible configurations, including opening geometry and distance between opposite walls adjacent to an opening with various heat release rate has been numerically studied. This paper aims to broaden the scope of the validation of the available correlations [1,2] for the fire propagation behaviours of full-scale U-shape geometry through flame height and heat flux analysis with various separation distance of sidewalls.
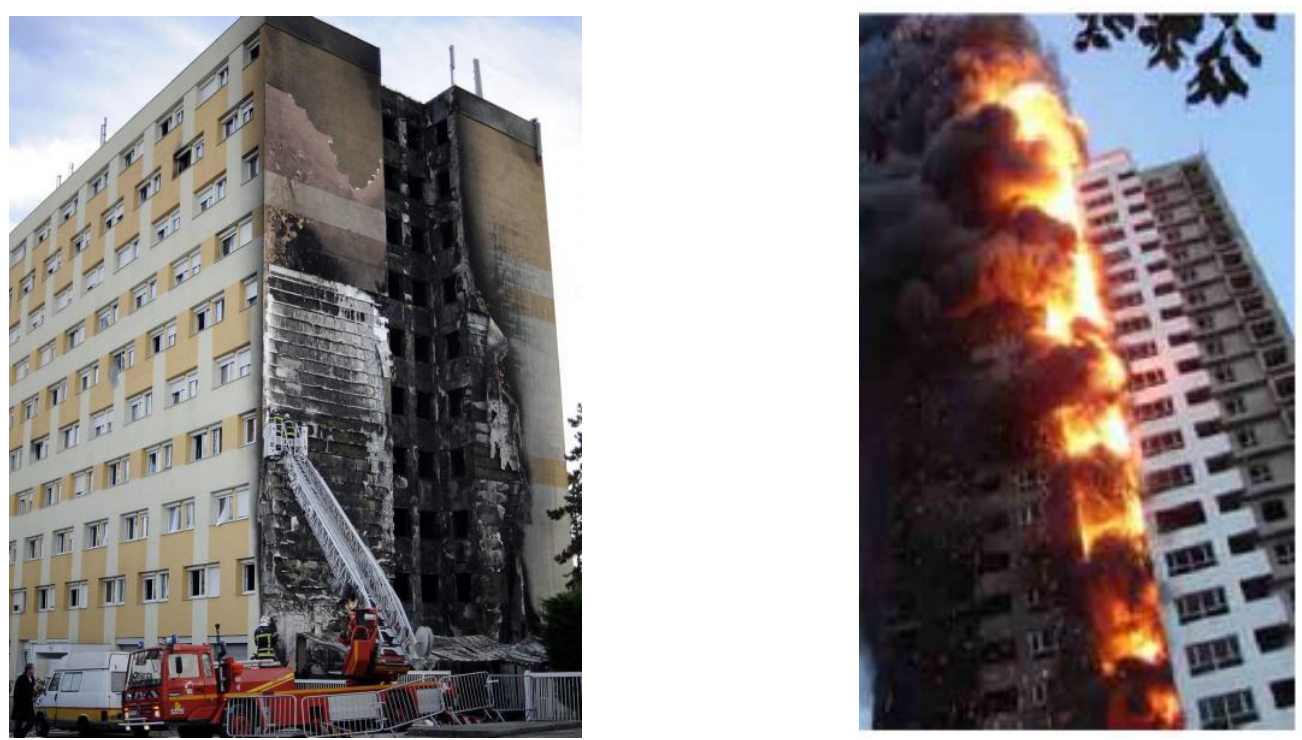

Figure 1. Real fire propagation of vertical U-shape building façade in France (left) and in China (right) both occurred in 2010 


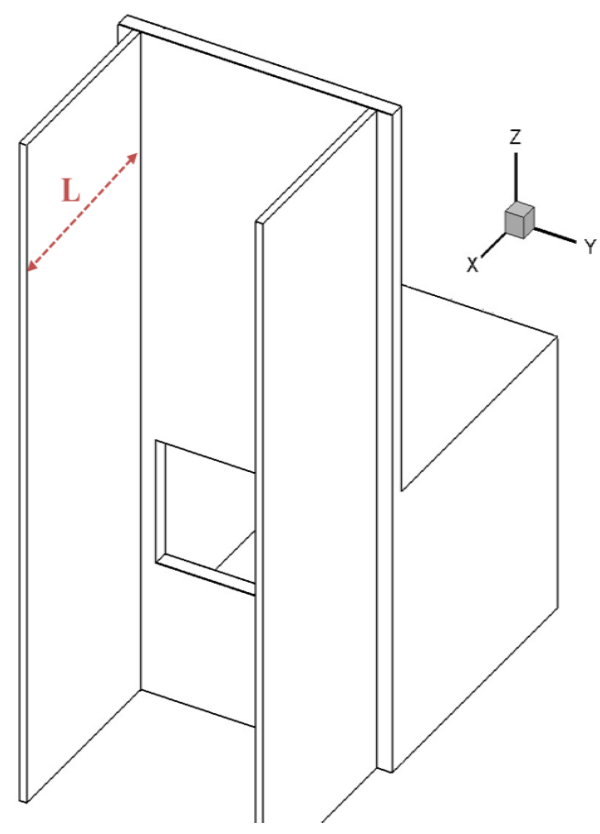

a)

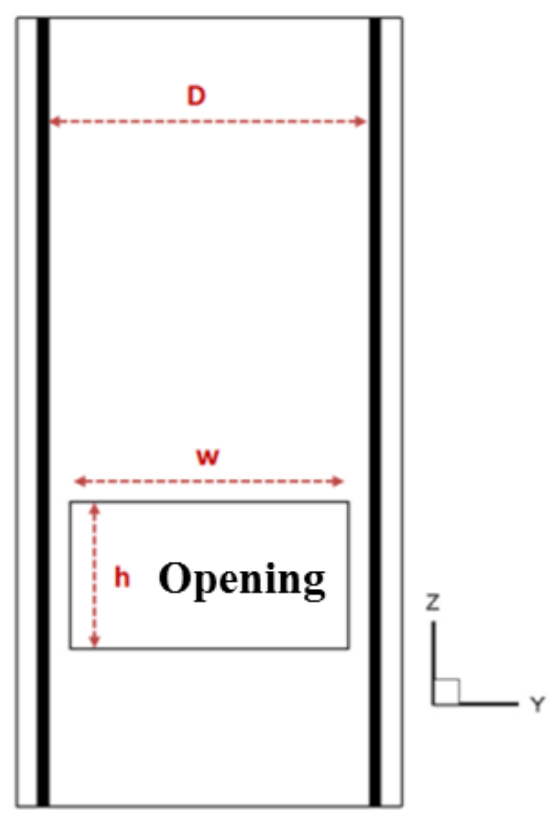

b)

Figure 2. General layout and characteristic configuration of a full-scale façade fire in numerical simulation: a) $3 \mathrm{~d}$ view; b) front view with opening geometry.

\section{NUMERICAL MODELLING}

A picture of 3D view of the FDS computational domain and the coordinate system in the numerical simulation are shown in Figure 2. Advanced fire physics model, which is the subject of the current work, requires state-of-the-art submodels (combustion, multidimensional participating radiation, soot formation, heat transfer, condensed fuel vaporization, etc.) coupled with the flowfield governing momentum solution. The basis of the analysis is the conservation equations of mass, momentum, energy and species, a set of three-dimensional elliptic, timedependent Navier-Stokes equations. The finite-difference technique is used to discretize the mathematical representation of the reacting flow phenomena of interest here, and can be found elsewhere [22].

In a Large Eddy Simulation, turbulence is modelled using a Deardorff's model via eddy viscosity as,

$\mu_{\mathrm{t}}=\rho \mathrm{C}_{\mathrm{v}} \Delta \sqrt{\mathrm{ksgs}_{\mathrm{sg}}}$

The model constant $C_{v}$ is set to the literature value of 0.1 [22]. The algebraic form of subgrid kinetic energy, $\mathrm{k}_{\mathrm{sgs}}$, is obtained from a scale-similarity model as proposed in FDS [22]. The filter width, $\Delta$, is attached to the grid size. The turbulent Prandtl number is assumed to be constant with the value of 0.5 [23]. 
The combustion processes are governed by the conservation equations for the mass fraction of the six major chemical species, such as fuel, $\mathrm{O}_{2}, \mathrm{CO}_{2}, \mathrm{H}_{2} \mathrm{O}, \mathrm{N}_{2}$ and soot via a single global reaction step for wood.

$$
\mathrm{C}_{3.4} \mathrm{H}_{6.2} \mathrm{O}_{2.5}+3.62\left(\mathrm{O}_{2}+3.76 \mathrm{~N}_{2}\right) \rightarrow 3.32 \mathrm{CO}_{2}+3.10 \mathrm{H}_{2} \mathrm{O}+0.08 C_{\text {soot }}+13.61 \mathrm{~N}_{2}
$$

The pine type of wood is chosen for the chemical reaction based on the available experimental database [24]. The heat release rate is calculated from the local reaction rate of fuel via an Eddy Dissipation Concept (EDC) [22].

$$
\dot{\mathrm{Q}}=-\frac{\rho}{\tau_{\text {mix }}} \min \left(\mathrm{Y}_{\mathrm{i}}, \frac{\mathrm{Y}_{\mathrm{O} 2}}{\mathrm{~s}}\right) \cdot \mathrm{H}_{\mathrm{eav}}\left(\mathrm{Y}_{\mathrm{O} 2}-\mathrm{Y}_{\mathrm{O} 2, \lim }\right) \cdot \Delta \mathrm{H}_{\mathrm{c}}
$$

Where $\Delta \mathrm{H}_{\mathrm{c}}$ is the amount of energy released per unit mass of fuel consumed, and taken as 17.5 $\mathrm{MJ} / \mathrm{kg}$ for pine type of wood $[24,25]$. The local key timescale, $\tau_{\text {mix }}$, is supposed to relate approximately to the three processes such as diffusion, subgrid-scale advection and buoyant acceleration [22]. The source term is multiplied by $\mathrm{H}_{\text {eav }}\left(\mathrm{Y}_{\mathrm{O} 2}-\mathrm{Y}_{\mathrm{O} 2, \mathrm{lim}}\right)$, where $\mathrm{H}_{\text {eav }}$ is the Heaviside unit step function, which is zero when its argument is negative $\left(\mathrm{Y}_{\mathrm{O}_{2}}<\mathrm{Y}_{\mathrm{O} 2 \text {,lim }}\right)$ and 1 when it is positive $\left(\mathrm{Y}_{\mathrm{O} 2}>\mathrm{Y}_{\mathrm{O} 2 \text {,lim }}\right.$ ). This implies that flame extinction occurs as the local oxygen concentration is below a critical value, $\mathrm{Y}_{\mathrm{O} 2, \mathrm{lim}}$, evaluated as,

$$
\mathrm{Yo}_{2, \lim }=\frac{\mathrm{C}_{\mathrm{p}}\left(\mathrm{T}_{\mathrm{f}}-\mathrm{T}_{\mathrm{m}}\right)}{\Delta \mathrm{H}_{\mathrm{o}}}
$$

Where $\Delta \mathrm{H}_{\mathrm{o}}(=13100 \mathrm{~kJ} / \mathrm{kg})$ is amount of energy released per unit mass of oxygen consumed, $\mathrm{T}_{\mathrm{f}}$ adiabatic flame temperature, $T_{m}$ bulk temperature of a control volume and $\mathrm{C}_{\mathrm{p}}$ specific heat. Note that all these parameters affect the history of externally venting flame propagation. In the current work, it is found that combustion at a stoichiometric fuel-air mixture allows to reproduce the experimental trend, signifying a positive argument of Heaviside function.

In FDS, soot production is derived from the fraction of the fuel mass that is converted into soot without taking into account the essential physical processes of soot formation and oxidation. With such soot yield approach, the predicted results are not improved using six radiation bands of $\mathrm{CO}_{2}$ and $\mathrm{H}_{2} \mathrm{O}$ due to an important production of soot even for a wellventilated fire. In the current simulations, it is assumed that soot is the most important combustion product controlling the thermal radiation from the flame and hot smoke. The gas behaves as a grey medium with one absorption coefficient without the spectral dependence. The grey gas assumption can lead to an over-prediction of the emitted radiation when soot production is small compared to the yields $\mathrm{CO}_{2}$ and water vapour. A radiative transfer equation is solved by using a discrete expression adapted to a finite volume method [22].

A wall-damping is treated by using a wall function for convective motion near the wall due to the coarse meshes used here [22]. The enclosure/façade walls with a thickness of $0.2 \mathrm{~m}$ are assumed to be thermally-thick. A one-dimensional heat conduction equation for the material temperature is solved using the thermo-physical properties in Table 1. The heat transfer equation is discretized by finite difference. The size of the cell size at the interior of the wall is 
selected automatically and is smaller than $\sqrt{\mathrm{k} / \rho \mathrm{c}_{\mathrm{p}}}$ where $\mathrm{k}$ denotes thermal conductivity, $\rho$ density and $c_{p}$ specific heat. By default, the solid mesh cells increase towards the middle of the material layer and are smallest on the layer boundaries. The cells number is chosen automatically according to the thickness of the material layer [22].

\section{RESULTS AND DISCUSSIONS}

In LES as used in FDS6 [22], the filter width of sub-grid viscosity is attached to the grid size, and thus, the numerical model uses the quantities that are mesh dependent. In order to have a reliable prediction, it is important to use an adequate mesh for capturing the primary momentum transport of turbulent pool fire. For an enclosure fire, the viscous sub-layer near the walls is thin, this constraint translates into large computational grid requirement with a mesh size of $\mathrm{mm}$ that is generally incompatible with full-scale fire simulations [5-7]. Nevertheless, $a$ priori estimates of the grid size using a characteristic length of pool fire $D^{*}$ are not trivial for starting the simulation [22]. By treating the expendable fuel (wood) source as a pool fire, a characteristic length of pool fire $D *$ is related to the heat release rate (HRR) as below [22]:

$$
D^{*}=\left(\frac{\dot{Q}}{\rho_{\infty} c_{p, \infty} T_{\infty} \sqrt{g}}\right)^{2 / 5}
$$

The HRR can be derived from the measured mass loss rate and the energy released per kilogram of fuel (wood). For this full-scale compartment fire, the peak in HRR is approximately up to 8 MW, giving a characteristic length, $D^{*}$ of $2.21 \mathrm{~m}$. Generally, the large-scale energy-containing eddies that are controlled by the inviscid terms can be completely described when the characteristic length $D^{*}$ is spanned by roughly sixteen computational cells. The grid size depends considerably on what we are trying to accomplish. In fact, the compartment quickly fills with smoke, and the layered structure in a compartment fire can be resolved using significantly fewer grid points compared to the structure of the flame. A relatively coarse mesh size of $10 \mathrm{~cm}$ was estimated, and then gradually refine the mesh until we do not see appreciable difference in the predicted results. A cell size of $10 \mathrm{~cm}$ is adequate solely for evaluation of the smoke temperature field of a sizable enclosure fire.

The work of Zhang [26] indicated that the domain extension is more efficacious in the wall fire normal x-direction, while is limited in the vertical z-direction and in the spanwise ydirection. It is found that extension of the computational domain beyond the vertical opening by one hydraulic diameter of the vent opening is sufficient for taking into account the interactions of internal and external flames. In the current compartment fire simulations, the overall computational domain is $6.5 \mathrm{~m}$ in the wall fire normal $\mathrm{x}$-direction, $12 \mathrm{~m}$ in the spanwise $\mathrm{y}$-direction and $12.5 \mathrm{~m}$ in the vertical z-direction, which is practically $3-6$ times of the hydraulic diameter of the vent opening of $2 \mathrm{~m}$, large enough to assume a zero gradient condition at the free boundaries. An excessive domain extension needs the use of a highly compressed grid system, and build-up of numerical error could produce spurious results over the course of a LES calculation due to commutation of the filtering operation [22]. The uniform grid system with a mesh size of $10 \mathrm{~cm}$ and a moderate computational domain are extensively used $[4,6,26]$, which offered the best tradeoff between accuracy and cost for large scale fire simulations.

\subsection{Validation from a full-scale flat façade fire}


A full-scale enclosure fire test conducted at CTICM [24] in France, as schematized in Figure 3, has been largely served for numerical model validation [25]. The internal compartment dimensions were $3.6 \mathrm{~m}$ in length $(\mathrm{x}), 3.6 \mathrm{~m}$ in width $(\mathrm{y})$ and $3.1 \mathrm{~m}$ in height $(\mathrm{z})$ equipped with an external flat façade wall measured $6 \mathrm{~m}$ in height $(\mathrm{z})$ and $3.6 \mathrm{~m}$ in width $(\mathrm{y})$. The fire compartment opening measured $1.4 \mathrm{~m}$ in height $(\mathrm{h})$ and $2.6 \mathrm{~m}$ in width $(\mathrm{w})$, corresponding to a window, is located at the façade wall.

The compartment and façade lining walls are made of the resistant gypsum plasterboards with a thickness of $0.2 \mathrm{~m}$. The physical properties, as presented in Table 1, of the experimental setup, such as density, thermal conductivity and specific heat in ambient conditions are used in the numerical simulation.

Table 1: Material thermo-physical properties for the façade and enclosure walls

\begin{tabular}{|l|l|l|l|l|}
\hline Parameters & $\begin{array}{l}\text { Thermal } \\
\text { conductivity } \\
(\mathrm{W} / \mathrm{m} . \mathrm{K})\end{array}$ & $\begin{array}{l}\text { Density } \\
\left(\mathrm{kg} / \mathrm{m}^{3}\right)\end{array}$ & $\begin{array}{l}\text { Thermal } \\
\text { specific capacity } \\
(\mathrm{J} / \mathrm{kg} . \mathrm{K})\end{array}$ & Thickness $(\mathrm{m})$ \\
\hline Façade & 0.2 & 450 & 1000 & 0.2 \\
\hline Ceiling & 0.2 & 450 & 1000 & 0.2 \\
\hline Wall & 0.45 & 1050 & 840 & 0.2 \\
\hline Floor & 1.6 & 2300 & 1000 & 0.2 \\
\hline
\end{tabular}

Aiming to simulate realistic building conditions, an expendable solid fuel (wood) is employed. Wooden cribs are typically used as the fuel load on compartment fires, as they have been shown to be representative of typical room furnishings and have good repeatability [24, 25]. There are six vertical profiles (A-F), and each of the profiles comprises 6 thermocouples positioned at regular intervals over the height of the façade wall (cf. Fig.3a, b).

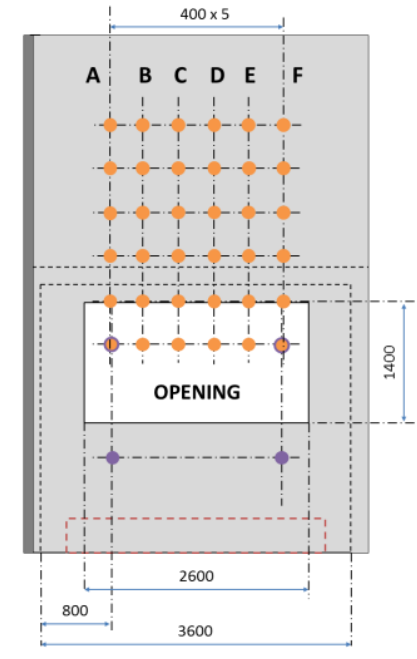

a)

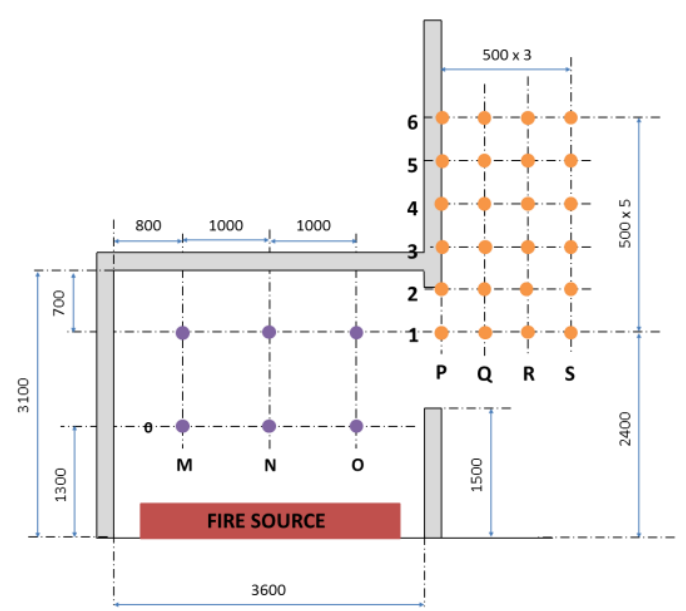

b) 
Figure 3. General layout and characteristic configuration of a full-scale façade fire test: a) Front view for the thermocouple locations; b) Side view for the thermocouple locations.

Predicting mass loss rate of wood cribs with the potential of burning away via heat and mass transfers is complex, and generally incompatible with full-scale fire simulations due to large computational grid requirement [25]. In the current numerical simulations, the wood cribs are in a simplified configuration in which the mass loss rate collected experimentally (cf. Fig.4) is prescribed with a pyrolysis surface area of $3.2 \times 3.2 \mathrm{~m}^{2}$ which is placed in the middle of the enclosure, slightly elevated at a height of $0.3 \mathrm{~m}$. The pine type of wood is chosen as in the experiments. FDS [22] manages to correctly predict the evolutions of the total HRR and the internal one inside the compartment, as presented in Figure 5. The heat release rate is calculated from the combustion model based on an Eddy Dissipation Concept (Eq.3). Integration of the local heat release rate over all cells with a volume $\Delta \mathrm{V}$ inside the enclosure allows to monitor the internal heat release rate.

Evolution of the HRR (cf. Fig.5) can be said to follow the four characteristic stages : 1) The initial growth, pre-flashover phase up to $300 \mathrm{~s}$, during which combustion is limited at the interior of the compartment with an identical value between the total and internal HRRs. 2) The fully developed, flashover phase, defined by the rapid increase in HRR to $8 \mathrm{MW}$, during which the flame front moves gradually from the vicinity of the fuel source due to lack of oxygen, expanding radially and horizontally towards the opening. This signifies the beginning of the external flame jets and quick flashes appearing at the exterior of the fire compartment. 3) The post-flashover phase during a long period of about $20 \mathrm{~min}$, the sustained external combustion of unburnt volatiles consistently covers the region above the opening; a large part (4 MW) of about $50 \%$ of the total energy is released outside along the façade. 4) The decay phase of external flaming during which flame jets appear intermittently outside the compartment, characterized by a burning transition back to fuel-control before auto-extinction is achieved to burnout of the fuel load.

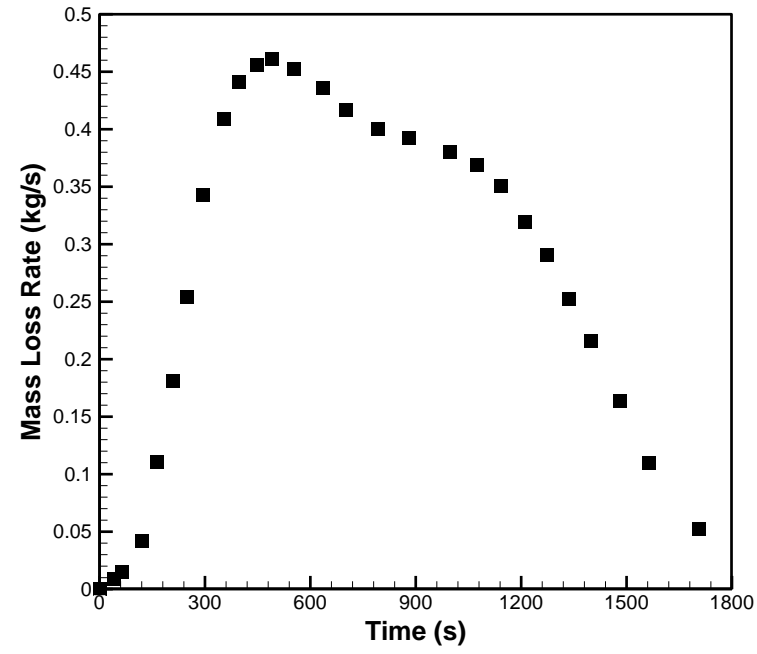

Figure 4. Evolution of the measured mass loss rate of the pine type of wood used as input data in numerical simulation

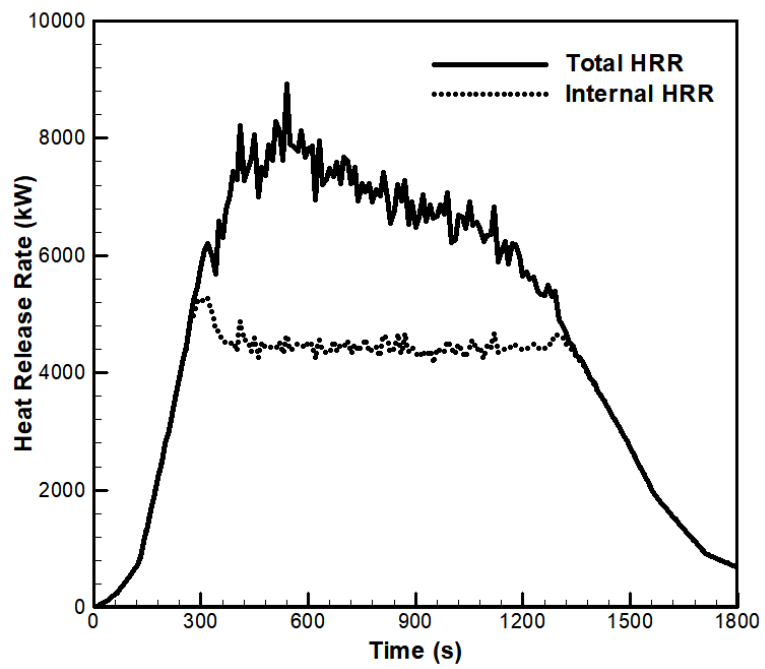

Figure 5. Predicted total heat release rate and internal one inside the compartment based on the measured mass loss rate 
Histories of the gas temperature along the façade wall are analysed. In fire environment, the temperature experimental data from thermocouple bead are radiation corrected. In order to compare the simulated and measured temperature data, the thermocouple model is incorporated into FDS6 [22]. The thermocouple model $\left(T_{T C}\right)$ is based on a simple balance for thermocouple bead and is informed by LES-based estimates of the rates of convective and radiative heat transfer, as follows :

$$
\rho_{T C} C_{T C} \frac{d T_{T C}}{d t}=\varepsilon_{T C}\left(U / 4-\sigma T_{T C}^{4}\right)+h\left(T_{g}-T_{T C}\right)=0
$$

Where $\mathrm{T}_{\mathrm{g}}$ denotes the gas temperature derived from a state equation, as $\mathrm{T}_{\mathrm{g}}=\mathrm{P} / \mathrm{RTM}, \varepsilon_{T C}$ the emissivity, $U$ the integrated radiative intensity and $h$ the heat transfer coefficient. Since the type of thermocouple used in the tests [24] is unknown, the default values proposed in FDS [22] for nickel are taken into account in the simulation.

The two methods based on both the gas temperature and thermocouple model are compared with the experimental data in Figure 6. The radiation heat flux to the thermocouples bead depends mainly on three factors such as flame size, concentrations of gaseous and particulate soot emitting species, and view factor from flame to the exposed thermocouples bead. The gas temperature near the wall at position P1 or P6 (cf. Fig.3b) is mainly controlled by convection, and contribution by radiation appears less important due to a decrease in view factor. The temperature form thermocouple model near the façade wall (position P) is slightly higher than the gas temperature. The positions Q1 and R1 are close to the opening with a normal distance beyond $0.5 \mathrm{~m}$ from the façade wall. Here the gas temperatures, $\mathrm{T}_{\mathrm{g}}$, are much lower as compared to thermocouple temperatures, $\mathrm{T}_{\mathrm{TC}}$. This is mainly attributed to the important contribution of radiation flux received by the thermocouples bead with an increase of view factor. However, any attempt to draw a general conclusion for some metrics is discouraged due to the uncontrollable factors such as fire size, chemical species, etc.

Generally, the thermocouple model $\left(T_{T C}\right)$ shows a remarkable agreement with measured values for a consistent and continuous behavior of externally venting flame. In fact, an intermittent zone of externally venting fire which coincides with forward pulsations of flame with a fluctuating, turbulent character is experimentally identified [27, 28]. The EDC type [22] is temperature independent combustion model, which is incapable of reproducing the frequencies of flame presence/absence in the intermittent zone at the top of fire plume. An overestimate of the temperature close to the opening ejected flame position Q6 is attributed to a reduced accuracy of LES combustion model (EDC) under intermittent-like conditions. A rigorous numerical study [29] using a similar combustion model on a vertical wall fire with a mesh size of $3 \mathrm{~mm}$ is incapable of identifying the intermittency values of the oscillation behavior. Note that both the local gas temperature [14, 30] and thermocouple model [29] are largely used for evaluation of limitations of fire models. Quantifying the uncertainty and accuracy of both the two methods in position Q6 ensures that overestimate of the temperature is attributed to the predictive capabilities of the fire models.

6a) at position P1 and P6 with a discrepancy within 5\%

6b) at position Q1 and Q6 with a discrepancy within 50\%

6c) at position R1 and R6 with a discrepancy up to $300 \%$ 

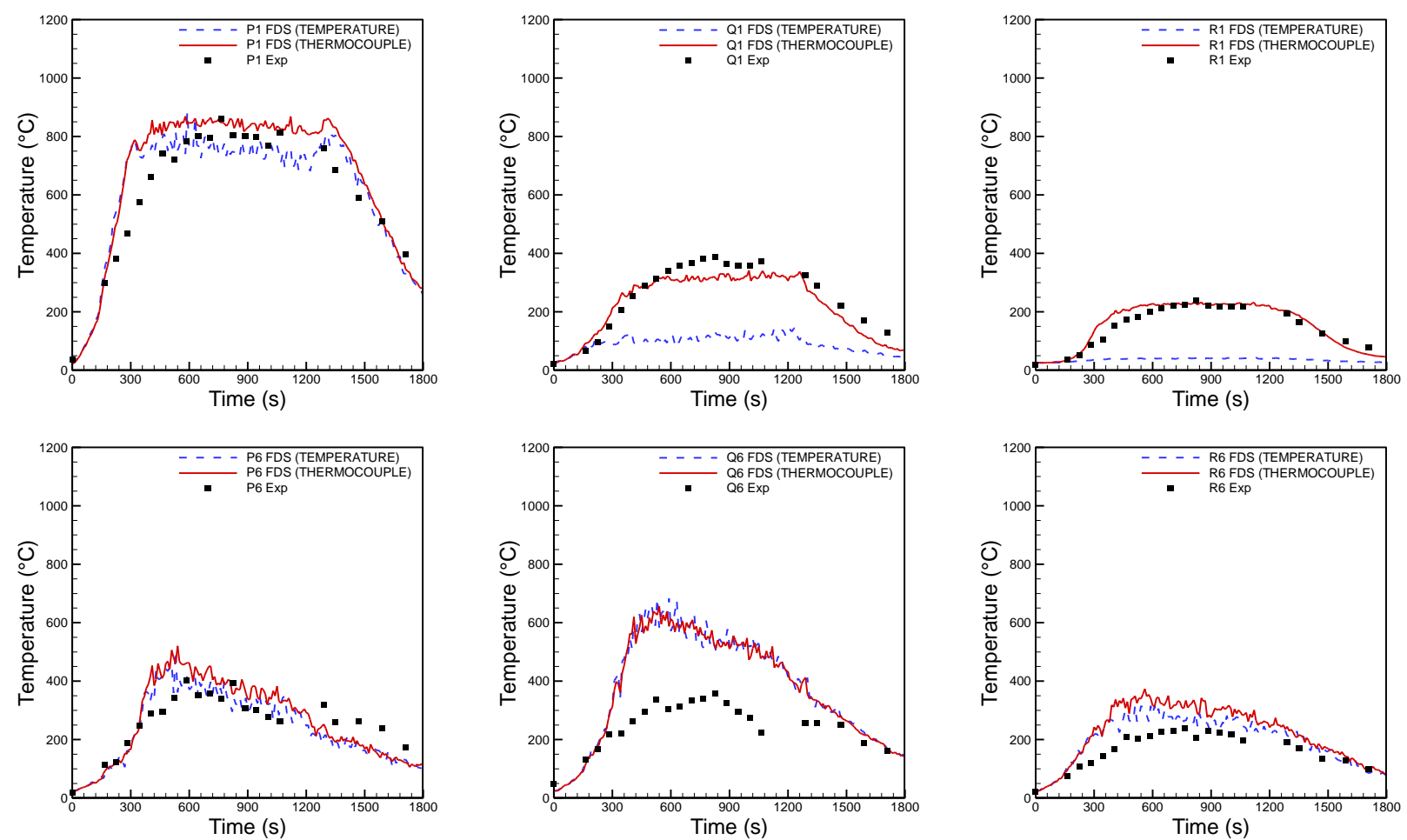

Figure 6. Comparison between the thermocouple model and gas temperature

The deviations of thermocouple model from gas temperature is an alternative to the classical experimental approach in which raw thermocouple data are corrected by radiation heat transfer effects. The thermocouple model is used to check the grid refinement from 20, 10 to 5 $\mathrm{cm}$ on the predicted temperatures for the positions P, Q and R (cf. Fig.3b) in Figures 7, 8 and 9. The measured temperatures which are averaged from the points $\mathrm{A}$ to $\mathrm{F}$ at each given elevation are also provided in these figures. The computation work was performed with a single mesh on a personal computer with a $3.2 \mathrm{GHz}$ Intel Xeon processor. With a mesh size of $10 \mathrm{~cm}$, the CPU time for a single simulation with a physical time of $1800 \mathrm{~s}$ and a time-step of about $10^{-3} \mathrm{~s}$ is approximately $50 \mathrm{~h}$. With halving of the grid size to $5 \mathrm{~cm}$, the numerical simulation was achieved only at $1100 \mathrm{~s}$ because the time required for the simulation increases by a factor of $2^{4}$ (a factor of two for each spatial coordinate, plus time) [22]. The fine mesh size of $5 \mathrm{~cm}$ is used just for judging the grid sensibility, and computations of the large-scale fire are limited to relatively coarse meshes of $10 \mathrm{~cm}$ everywhere $[5,6,7,26]$.

It can be noticed that the numerical results with a large mesh size of $20 \mathrm{~cm}$ do not match the measured ones near the wall region $(\mathrm{P})$ particularly far away from the opening. As compared to the experimental data, change of the predicted temperature plots along the façade by using the medium $(10 \mathrm{~cm})$ and fine $(5 \mathrm{~cm})$ mesh sizes is less than $5 \%$. This confirms that a mesh size of $10 \mathrm{~cm}$ gives practically a grid independent resolution, and thus is considered as appropriate for the purposes of this work. The predictions are in remarkable agreement with experimental 
results for positions $\mathrm{P}$ near the façade wall (cf. Fig.7) and R in the plume region (cf. Fig.9), implying that the flame thickness is correctly reproduced. A good estimation of near-wall thermal field (position P) allows to calculate properly the contribution of the heat convection near façade wall. Whereas, at each height, the temperatures are overestimated at position Q (cf. Fig.8), corresponding to the intermittent flame zone. In the other hand, the experimental database in Ref.[24] does not provide a complete description of the total uncertainty in the experimental temperature measurements. To the best knowledge of the authors, the response time of the thermocouples used in the experiment is close to a second by including thermal mass inertia and accumulation of soot particles. Thus, the uncertainty in the measurement of gas temperature by using thermocouples is estimated within $5-10 \%$ by taking into account a multitude of potential errors, including surface reactions, radiation, stem loss, etc. Besides, the humidity of pine type of wood [31] used in the tests [24] was not experimentally identified. Consequently, use of the measured wood mass loss rate (cf. Fig.4) in the numerical simulation may cause an overestimation of the HRR (cf. Fig.5), which affects the predicted temperature distribution. It seems most likely that the discrepancies are due to a combination of the experimental uncertainties and the possible error in the numerical simulation by neglecting the water evaporation rate.

7a) at position $\mathrm{P} 1$ and $\mathrm{P} 2$ with a discrepancy within $5 \%$

7b) at position $\mathrm{P} 3$ and $\mathrm{P} 4$ with a discrepancy within $30 \%$

7c) at position P5 and P6 with a discrepancy within $25 \%$
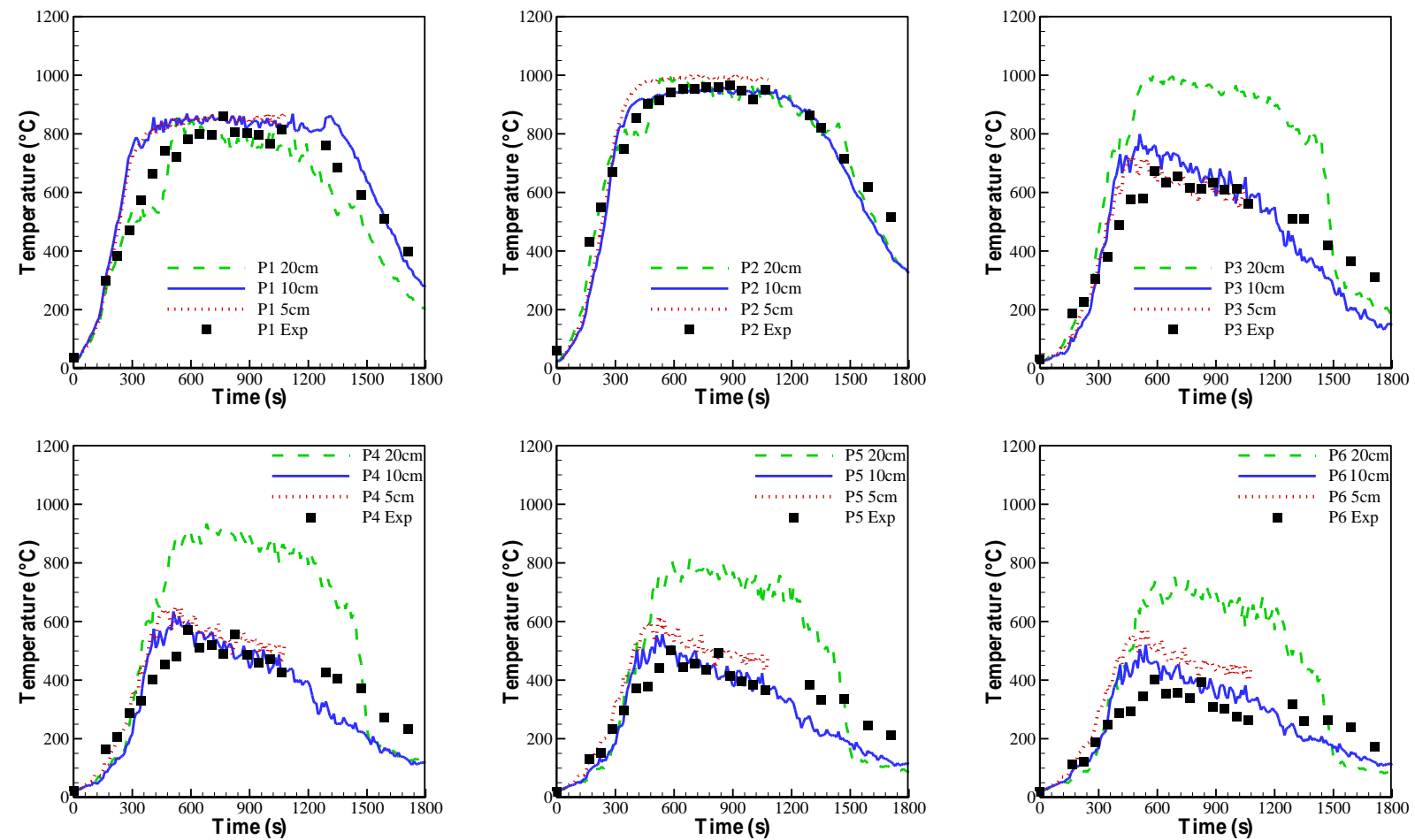
Figure 7. Influence of the mesh size varying from 5,10 to $20 \mathrm{~cm}$ on the predicted external temperatures at position $\mathrm{P}$.

8a) at position Q1 and Q2 with a discrepancy within 30\%

8b) at position Q3 and Q4 with a discrepancy within 25\%

8c) at position Q5 and Q6 with a discrepancy within 35\%
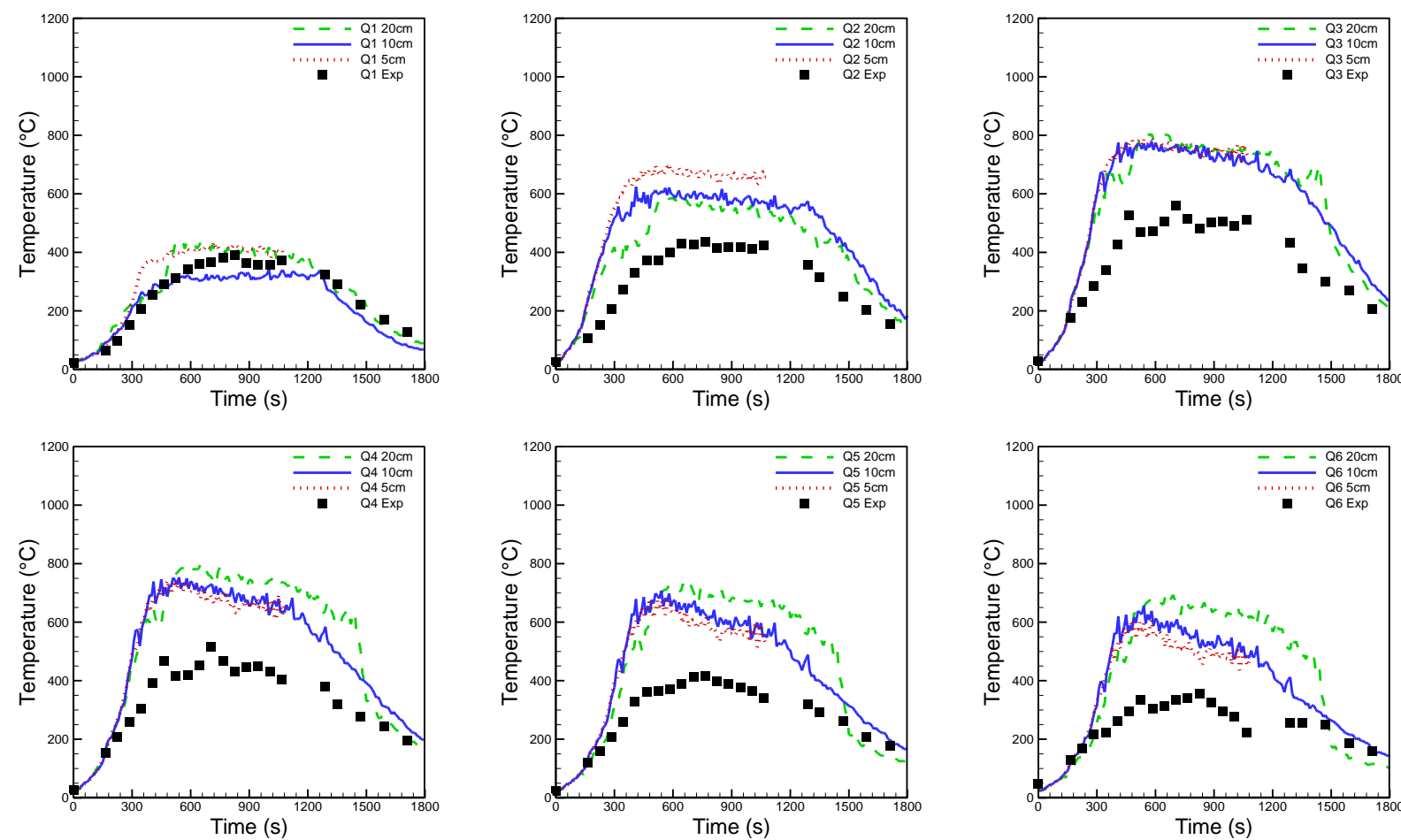

Figure 8. Influence of the mesh size varying from 5,10 to $20 \mathrm{~cm}$ on the predicted external temperatures at position $\mathrm{Q}$.

9a) at position R1 and R2 with a discrepancy within 5\%

9b) at position R3 and R4 with a discrepancy within $30 \%$

9c) at position R5 and R6 with a discrepancy within $30 \%$ 

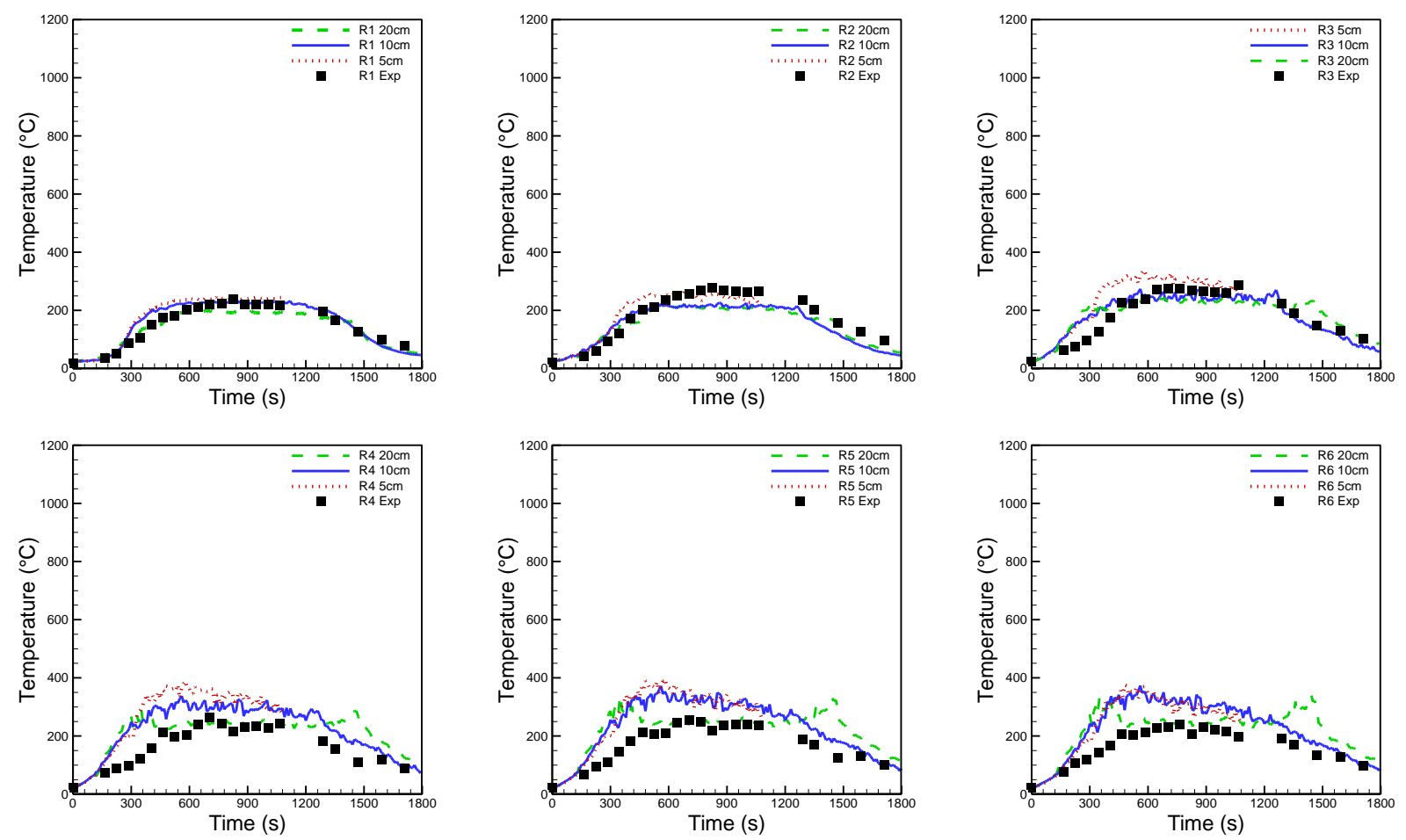

Figure 9. Influence of the mesh size varying from 5,10 to $20 \mathrm{~cm}$ on the predicted external temperatures at position $\mathrm{R}$.

Figure 10 shows the evolution of the predicted temperature, averaged from the 12 measurement points inside the compartment (cf. Fig.3b). As expected, the predicted temperature with a mesh size of $20 \mathrm{~cm}$ is far away from the experimental data. Globally, the model appears to accurately estimate the gas temperature during the quasi steady state period between 400 and 1200 seconds with a grid size of $10 \mathrm{~cm}$. These results show a similar trend to the findings in the Desanghere's work [25] using the version FDS2 for the same compartment fire and experimental data. The subgrid model in FDS is known as dissipative with a mesh size of $\mathrm{cm}$ [22], and lacks the ability to predict the transient phenomena under laminar-like conditions during the fire decay phase after $1500 \mathrm{~s}$. A more rapid decrease of the predicted temperature inside the enclosure may be attributed to the overestimate of the fresh-air entrainment towards the enclosure during the fire extinction phase. 


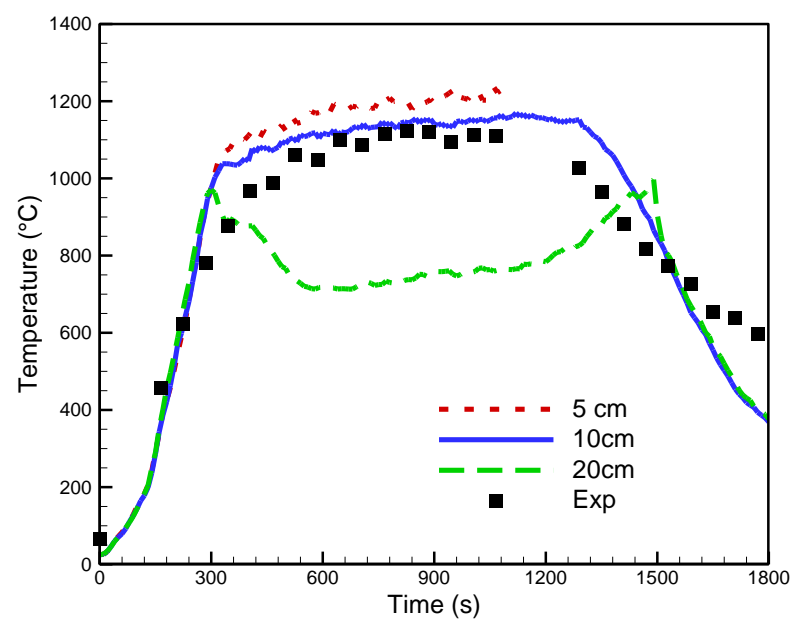

Figure 10. Influence of the grid size on the mean temperature inside compartment with a difference varying from $50 \%$ to $5 \%$ for a mesh size of $20 \mathrm{~cm}$ and $10 \mathrm{~cm}$, respectively.

\subsection{Influence of the sidewalls on the flame ejecting behavior}

In the numerical simulation, a time-dependent heat release rate, similar to the one in Fig.5, is used with a prescribed peak value varying from 1 to $8 \mathrm{MW}$. Scaling laws [32, 33] via the concept of Global Equivalence Ratio (GER), are proposed for comparing the full-scale simulations results with the correlations $[1,2]$ derived from small-scale tests. The global equivalent ratio (GER), $\phi=\dot{\mathrm{m}}_{\text {fuel }} \mathrm{s} / \dot{\mathrm{m}}_{\text {air }}$, is calculated from the fuel supply rate $\left(\dot{m}_{\text {fuel }}\right)$, air inflow rate $\left(\dot{m}_{\text {air }}\right)$ and stoichiometric coefficient $\mathrm{s}$.

The semi-empirical correlation [33] is derived from a mass balance in conjunction with the experimental data which allows to adjust the constant related to the flow coefficient $(0.41)$. At a certain opening geometry, the mass outflow rate $\left(\dot{m}_{\text {out }}\right)$ from the compartment is calculated as follows:

$$
\dot{m}_{\text {out }}=0.41 \rho_{a} A \sqrt{h}
$$

This implies that the height of the opening (h) has an influence more significant than the opening width $(\mathrm{w})$. The mass inflow rate can be derived from the mass conservation at the opening:

$$
\dot{m}_{\text {air }}=\dot{m}_{\text {out }}-\dot{m}_{f u e l}
$$

The dimensionless internal heat release rate $\left(\dot{Q}_{i n}^{*}\right)$ is defined as follows:

$$
\dot{Q}_{i n}^{*}=\frac{\dot{Q}_{i n}}{\dot{m}_{\text {air }} Y_{O_{2}} \Delta H_{O_{2}}}
$$

Here, the internal heat release rate $\left(\dot{Q}_{i n}\right)$ is derived from the air entrainment inside compartment:

$$
\dot{Q}_{i n}=\dot{m}_{\text {air }} Y_{O_{2}} \Delta H_{O_{2}}=\left(\dot{m}_{\text {out }}-\dot{m}_{f u e l}\right) Y_{O_{2}} \Delta H_{O_{2}}
$$


Here, $Y_{\mathrm{O}_{2}}$ and $\Delta \mathrm{H}_{\mathrm{O}_{2}}$ are respectively the ambient mass fraction of oxygen and the amount of energy released per unit mass of oxygen consumed. The external heat release rate, $\dot{Q}_{e x}$, is derived from the total heat release rate, $\dot{\mathrm{Q}}_{\text {tot }}$, and internal one, $\dot{\mathrm{Q}}_{\mathrm{in}}$, as follows:

$$
\dot{\mathrm{Q}}_{\mathrm{ex}}=\dot{\mathrm{Q}}_{\mathrm{tot}}-\dot{\mathrm{Q}}_{\mathrm{in}}
$$

Influence of the sidewalls distance (cf. Fig.2) on the spill flame height due to burning the excess fuel gas $\left(\dot{Q}_{\text {ex }}\right)$ ejected from an opening was experimentally investigated by Lu [1] from a reduced scale enclosure with a HRR below $60 \mathrm{~kW}$. A global dimensionless parameter, $\mathrm{K}$, is assumed to describe the mean flame height as a function of the separation distance $\mathrm{D}$, the characteristic length scale of the opening size $(\mathrm{h}, \mathrm{w})$ in conjunction with the competition of momentum and buoyancy flux at the opening under ventilated condition. The parameter, $\mathrm{K}$, represents the flame height $\left(\mathrm{H}_{\mathrm{D}}\right)$ for a distance $\mathrm{D}$ normalized by the one $\left(\mathrm{H}_{0}\right)$ of a flat façade, as follows:

$$
\mathrm{K}=\frac{\mathrm{H}_{\mathrm{D}}}{\mathrm{H}_{0}}=\mathrm{f}(\mathrm{w}, \mathrm{h}, \mathrm{D}, \mathrm{L})
$$

The detailed formulation for the parameter $\mathrm{K}$ can be found elsewhere [1].

In order to establish various under-ventilated fire conditions, seven scenarios with different fire load and opening dimensions were selected, as summarized in Table 2. For each Case 1 to 7 , the separation distance $\mathrm{D}$ varies from $2.6,2.8,3.6,4.4,6,8 \mathrm{~m}$ up to $\infty$ corresponding to a flat façade. The depth of the opposed sidewalls (cf. Fig.2) is fixed at L=3 m, and this allows to focus solely on the influence of the separation distance on the flame ejecting behavior.

Table 2. Summary of simulation scenarios with different opening dimension and HRR

\begin{tabular}{|c|c|c|c|c|c|c|c|}
\hline Parameter & Case & Case & Case & Case & Case & Case & Case \\
& 1 & 2 & 3 & 4 & 5 & 6 & 7 \\
\hline $\mathbf{w}(\mathbf{m})$ & 2.0 & 2.0 & 2.0 & 2.6 & 2.6 & 2.6 & 3 \\
\hline $\mathbf{h}(\mathbf{m})$ & 1.8 & 1.4 & 1.4 & 1.4 & 1.5 & 1.4 & 1.4 \\
\hline HRR (MW) & 6.5 & 6.5 & 5.5 & 6.5 & 6.5 & 5.5 & 6.5 \\
\hline
\end{tabular}

Turbulent flames exhibit a pulsing behavior. A mapping flame luminosity technique [1, $27,34]$ was developed to measure the mean flame height through a series of continuous images recorded using a CCD camera. The selected luminosity threshold corresponding to a continuous flame presence probability of 0.95 is used. It was checked that the so-determined persistent flame corresponds to a gas temperature of about $500^{\circ} \mathrm{C}[27,34]$. Note that an alternative for the description of the flame structure is based on the $\mathrm{CH}^{*}, \mathrm{OH}^{*}$ radicals formation zone [35], but it is not applicable to a full-scale fire due to both the cost and difficulty in the measurement of such species.

LES approach provides an instantaneous gas temperature output, $\bar{\phi}_{\mathrm{i}}$, and the timeaveraged quantity, $\hat{\phi}$ over a range of the computational time is obtained as, 


$$
\hat{\phi}=\frac{\sum_{\mathrm{i}=1}^{\mathrm{N}} \bar{\phi}_{\mathrm{i}} \Delta \mathrm{t}_{\mathrm{i}}}{\sum_{\mathrm{i}=1}^{\mathrm{N}} \Delta \mathrm{t}_{\mathrm{i}}}
$$

For each case, the temperature is averaged over a steady state period of $600 \mathrm{~s}$ during a physical time of $1800 \mathrm{~s}$ for determining the flame shape. As an illustration, the predicted, time-averaged temperature fields for Case 4 are shown in Figure 11(a-c) for three separation distances. The air supply rate is much less than the stoichiometric requirements inside the enclosure, inducing a more important ejection of flammable fuel-rich vapour cloud from the opening. There is quasi-steady spill burning characterized by the two regions of the flame one inside the box near the fuel source, and the other outside the box. Outside the enclosure, the height, $\mathrm{H}_{\mathrm{f}}$, of the visible flame past the opening from the ground level, corresponds to the zone where the temperature is higher than $500^{\circ} \mathrm{C}$ which is of particular concern for the radiation heat flux [17]. With an increase of the separation distance, $\mathrm{D}$, the flame is detached from the façade wall, accompanied by a remarkable decrease of the flame height (cf. Fig.11a). As the sidewalls are adjacent directly to the opening (cf. Fig.11c), the entrainment of air mostly occurs from front of the opening and the flame is attached to the façade wall. Otherwise, the increase of entrainment from side of the opening makes the flame detachment from the façade wall (cf. Fig.11b).

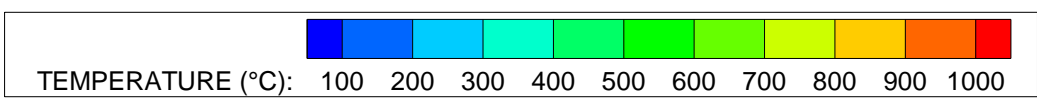

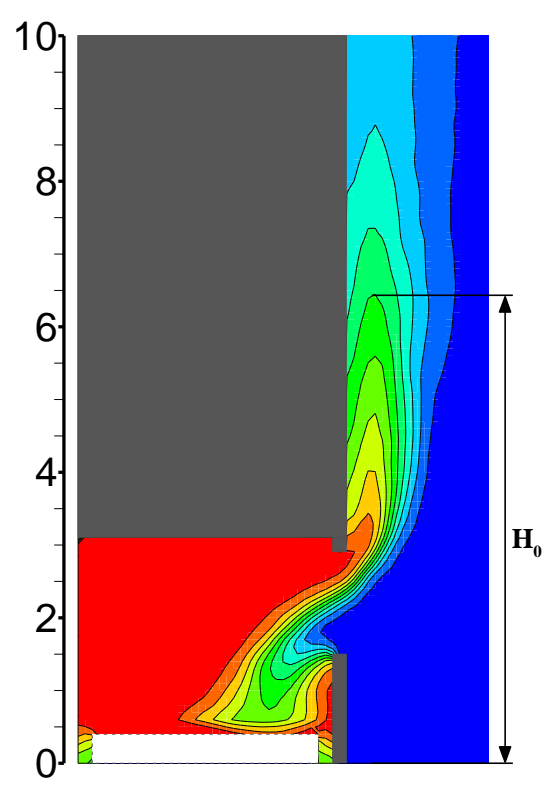

11a) $\mathrm{D}=\infty$

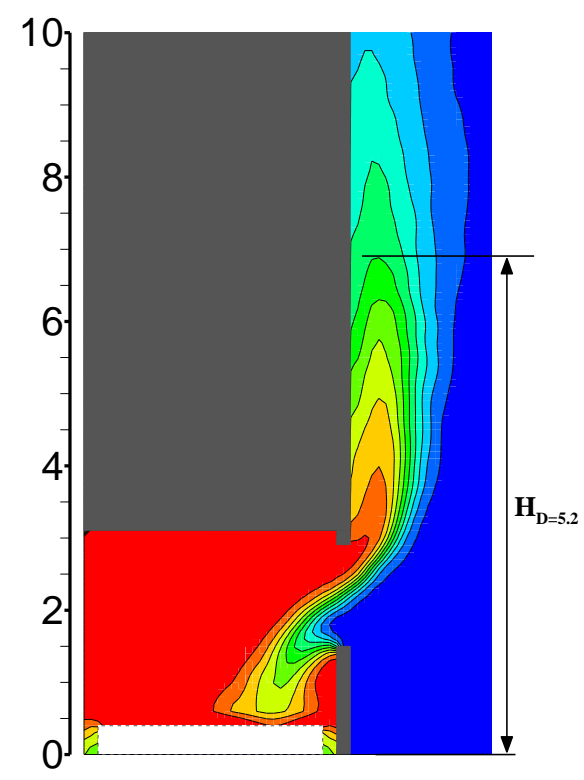

11b) $\mathrm{D}=5.2 \mathrm{~m}$ 


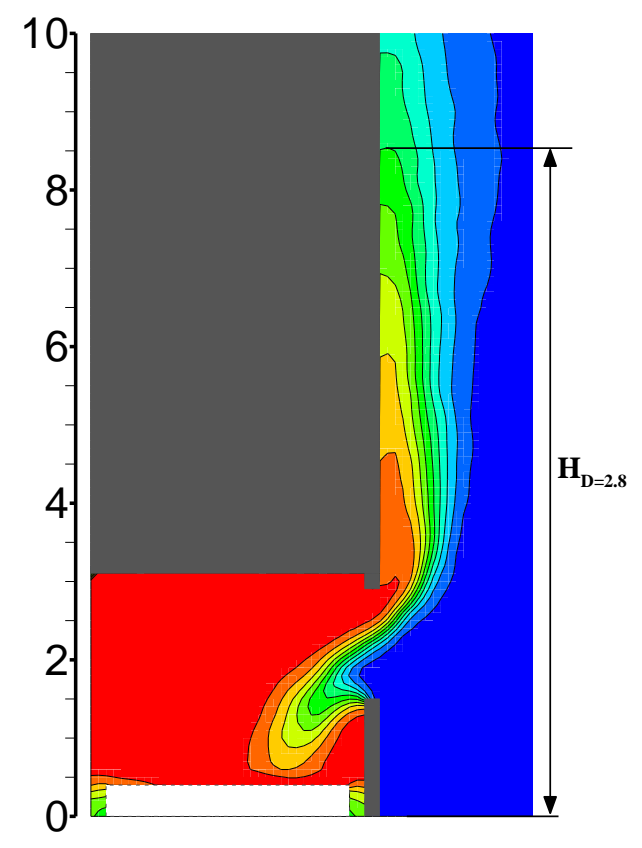

11c) $\mathrm{D}=2.8 \mathrm{~m}$

Figure 11. Distribution of the predicted time-averaged gas temperature on the vertical symmetric plane at $\mathrm{y}=1.8 \mathrm{~m}$ for Case 4 .

The predicted ratio, $\mathrm{K}=\mathrm{H}_{\mathrm{D}} / \mathrm{H}_{0}$, is used to make quantitative comparison with the correlation (12) in Figure 12 as a function of the normalized separation distance D/w varying from 1 to 7 . The predicted ratio, $\mathrm{K}$, follows closely the experimental or correlation trend with a nonlinear relation between the ratio $\mathrm{K}$ and the separation distance. It is found that an increase of the separation distance between the sidewalls, $\frac{\mathrm{D}}{\mathrm{w}}$, from 1 to 3 causes sensitively a reduction in the external flame height. A further increase of the distance between the sidewalls, $\frac{\mathrm{D}}{\mathrm{w}}$, beyond 3 brings about a progressive decrease of the ratio $\mathrm{K}$, consistent with the experimental observation [1]. The influence of the sidewalls on the externally venting flame height becomes negligible for the normalized distance, $\frac{\mathrm{D}}{\mathrm{w}}$, higher than 5. Globally, both the correlation (12) and the prediction match approximately the experimental trend within $10 \%$ uncertainty. The correlation (12) proved to be valid for a wide range of conditions using experimental data and are also validated by CFD simulation results for a full-scale façade fire. Note that these results are valid only for inert façade, and should not be directly extrapolated to fire propagation over a façade assembly including an insulation inflammable materials. 


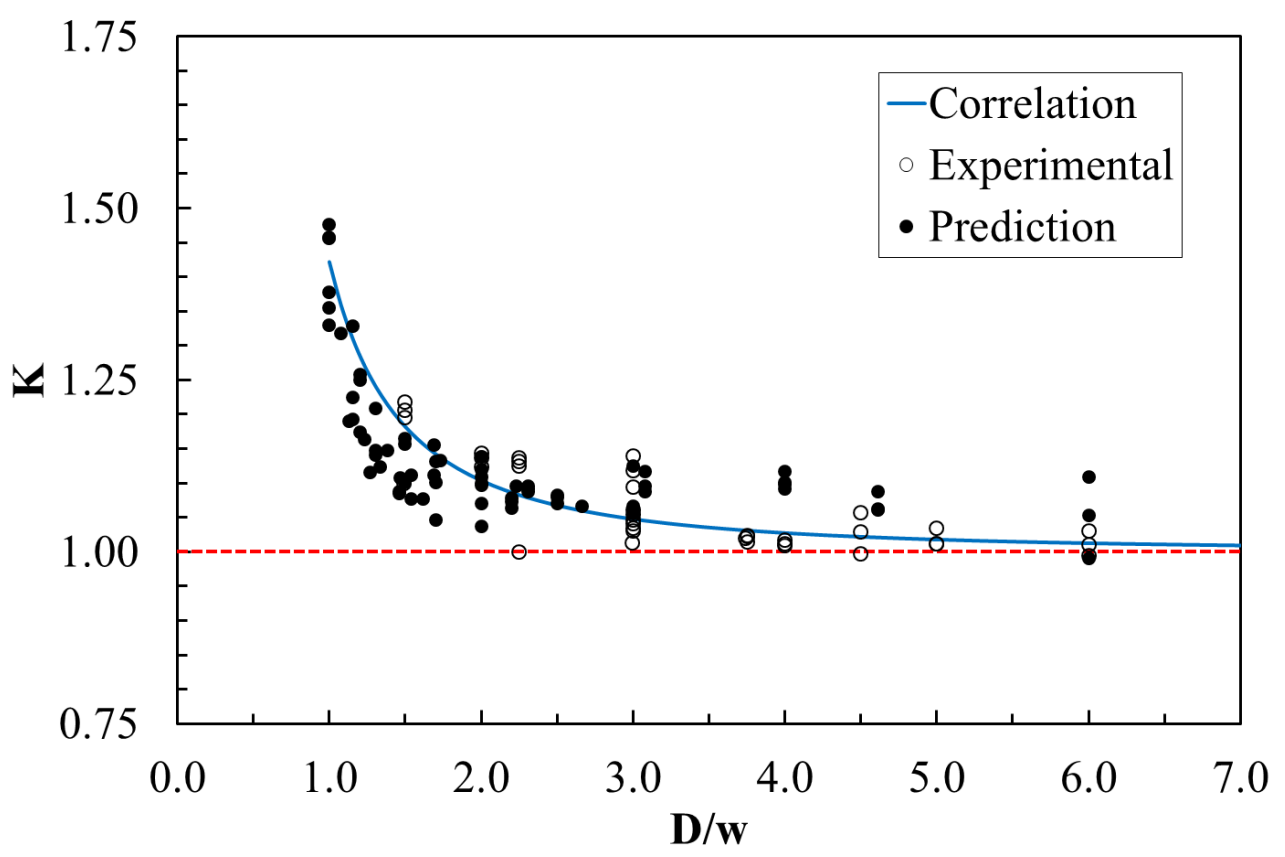

Figure 12. Comparison of dimensionless flame height between correlation from small-scale tests and numerical simulation from a full-scale compartment as a function of the normalized separation distance $(\mathrm{D} / \mathrm{w})$ within $10 \%$ difference

In Eq.(12) for the ratio $\mathrm{K}$, the spill flame height of a flat façade, $\mathrm{H}_{0}$, can be determined using the correlation (14) which was developed from a reduced scale compartment fire in conjunction with the experimental data [2]. This correlation is typically a function, f, related to the opening factor of a compartment $(\mathrm{w}, \mathrm{h})$ and the dimensionless external heat release rate, $\dot{\mathrm{Q}}_{\mathrm{ex}}^{*}$.

$$
\mathrm{H}_{0}=\mathrm{f}\left(\mathrm{w}, \mathrm{h}, \dot{\mathrm{Q}}_{\mathrm{ex}}^{*}\right)
$$

The detailed formulation for $\mathrm{H}_{0}$ can be found elsewhere [2]. The parameter $\dot{\mathrm{Q}}_{\mathrm{ex}}^{*}$ is related also to the opening factor and the ambient air properties $\left(\rho_{\infty}, C_{p}, T_{\infty}\right)$ as follows:

$$
\dot{\mathrm{Q}}_{\mathrm{ex}}^{*}=\frac{\dot{\mathrm{Q}}_{\mathrm{ex}}}{\rho_{\infty} \mathrm{C}_{\mathrm{p}} \mathrm{T}_{\infty} \mathrm{A} \sqrt{\mathrm{gH}}}
$$

The external heat release rate, $\dot{\mathrm{Q}}_{\mathrm{ex}}$, due to the burning excess fuel gas ejected from opening, is determined from Eq.(11).

In the numerical simulation, a range of 1 to $3 \mathrm{~m}$ with a regular interval of $0.2 \mathrm{~m}$ is chosen for the opening height $(\mathrm{h}) /$ width $(\mathrm{w})$ in addition to a HRR ( $\dot{\mathrm{Q}})$ varying from 1 to $8 \mathrm{MW}$ with a uniform interval of $0.5 \mathrm{MW}$. Different fire scenarios were simulated by combining the three parameters such as $\dot{Q}, h$ and $w$ for providing various external HRR values which influence directly the façade fire development. A few numerical data points compare with available correlation results in Fig.13 for identifying the façade flame height dependence on the 
dimensionless external HRR. It is clear that the correlation (14) ignores the flame appearance outside the compartment when $\dot{Q}_{\text {ex }}$ tends to zero for GER below 1. Whereas, it was experimentally observed [1-3] that when the fire is still fuel controlled, i.e. the GER is close but less than unity, the further evolved flames in the ceiling jet may become long enough to eject from the compartment opening. The numerical model is found to be able to predict the presence of the external flame in the situation for GER below 1. Globally, the overall evolution of predicted flame height follows closely the correlation trend as a function of the external HRR. Note that the numerical model exhibits a more conservative behavior with an overprediction of $40 \%$ as compared to the correlation (14). This may be attributed to the overestimation of the gas temperature (cf. Fig.8), which affects the externally venting flame behaviour via acceleration of the buoyancy-induced flow along the façade. Moreover, a similitude between a full scale and a reduced scale compartments cannot be totally preserved due to the confinement effect [36] influencing the turbulence development of the ejected fire. Besides, the discrepancy may partly be due to different identification of the visible flame shape in the experiment and the numerical simulation.

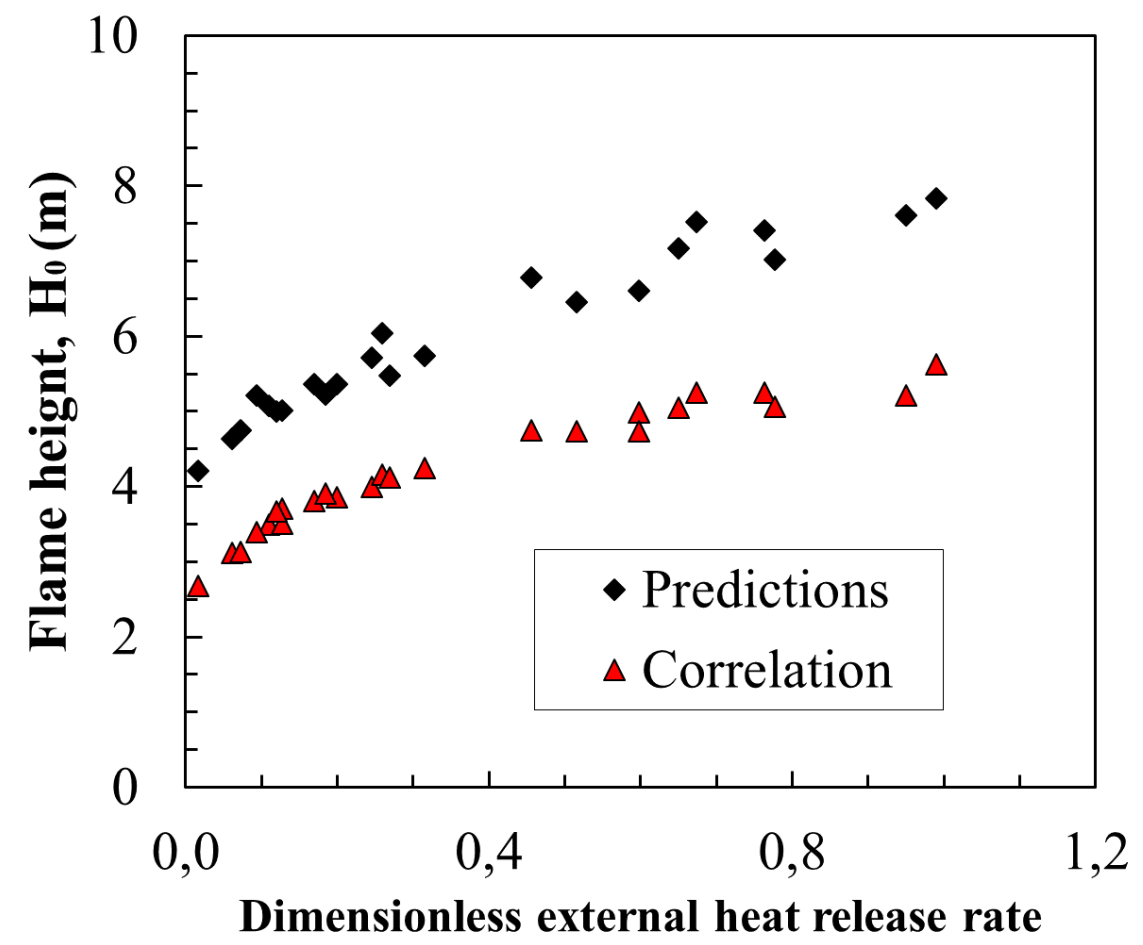

Figure 13. Comparison of the flame height between prediction and correlation as a function of the dimensionless external HRR within $40 \%$ difference by combining the three parameters such as $\dot{Q}, h$ and w.

As an illustration in Figure 14(a, b) for a heat release rate of $1.5 \mathrm{MW}$, the opening geometries affect not only the flame height, but also the fire plume structure. With a reduction of opening area from $4.2 \mathrm{~m}^{2}(\mathrm{w}=3.0 \mathrm{~m}, \mathrm{~h}=1.4 \mathrm{~m})$ to $3.6 \mathrm{~m}^{2}(\mathrm{w}=2.0 \mathrm{~m}, \mathrm{~h}=1.8 \mathrm{~m})$, the flame (cf. Fig. 14b) is detached from the façade wall with a remarkable volume growth of the thermal plume. The excess heat release rate of the fuel burning outside the opening with a reduced area becomes high enough to produce flames controlled by three-dimensional air entrainment. 


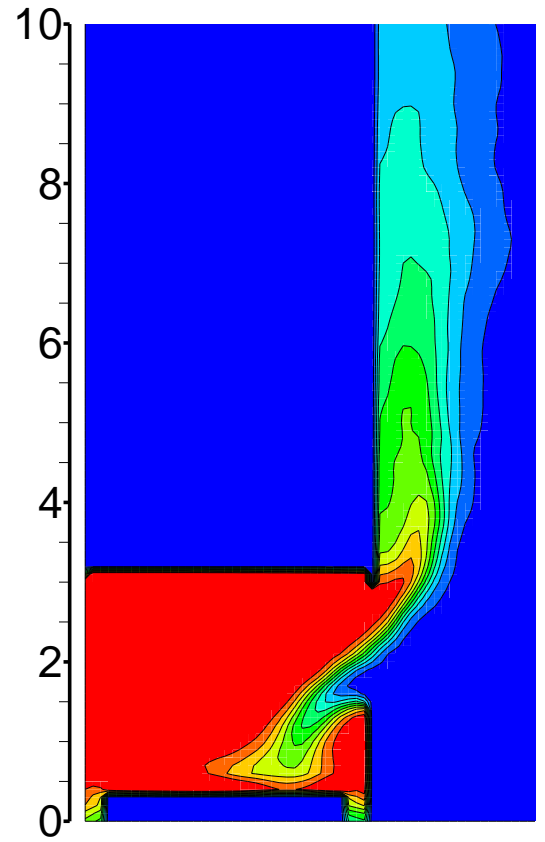

14a) $\mathrm{w}=3.0 \mathrm{~m}, \mathrm{~h}=1.4 \mathrm{~m}$

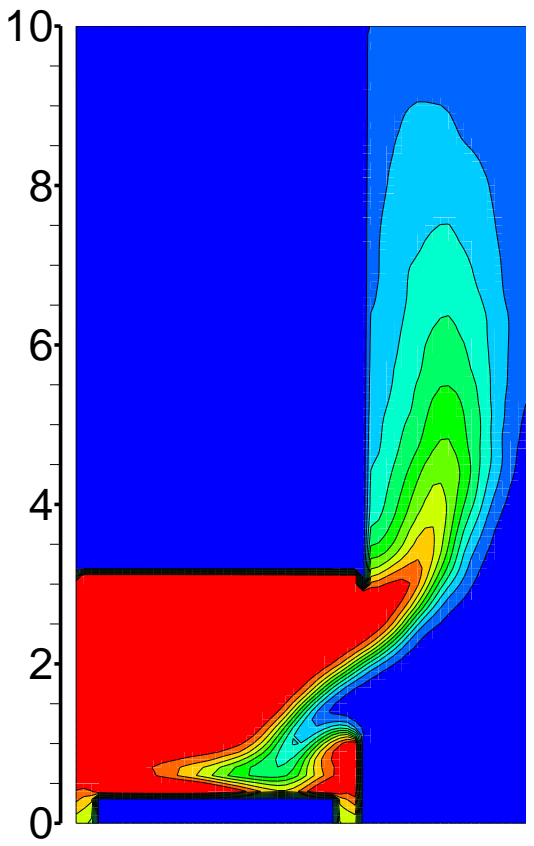

14b) $\mathrm{w}=2.0 \mathrm{~m}, \mathrm{~h}=1.8 \mathrm{~m}$

Figure 14. Influence of the opening geometries as $\mathrm{h}$ and $\mathrm{w}$ on distribution of the predicted timeaveraged gas temperature for a heat release rate of $1.5 \mathrm{MW}$.

It is found from Fig. 14 that the opening geometries control the supply of air towards the compartment, influencing directly the excess heat release rate inside enclosure. Figure 15 shows the evolution of dimensionless internal HRR, $\dot{Q}_{i n}^{*}$ (Eq.9) as a function of the GER from both the numerical simulation and the correlation. As for the flame height, $\mathrm{H}_{0}$ (cf. Fig.13), a series of fire simulations were conducted by combining also the three parameters such as $\dot{\mathrm{Q}}, \mathrm{h}$ and $\mathrm{w}$ for providing various global equivalent ratios (GER) which influence significantly the sustained internal combustion and unburnt volatiles formation. A few numerical data points compare with available correlation results in Fig.15 for identifying the dependence of the dimensionless internal HRR on GER. The experimental investigations [1, 2, 3, 32, 33] indicate that with GER below 1, there is enough air supply for burning all the released fuel inside enclosure, corresponding to an over-ventilated fire. The unity of GER implies that the amount of air corresponds exactly to the amount needed to react with all the fuel released from the pyrolysis. The $\dot{Q}_{i n}^{*}$ below 1 implies that a little part of the combustible gases is ejected through the opening and burnt outside. With GER higher than 1, air inside the compartment no longer allows combustion of all pyrolysis gases. The fundamental research [37, 38] shows that fire exhaust occurs as fuel-air mixture reaches a rich limit of flammability. The correlation (9) ignores the fire dynamics under lowered oxygen vitiation enclosure. By using this type correlation, at a certain opening geometry, the critical internal HRR is limited only by air supply rate, and it remains constant with a unity value even the fuel-air mixture is beyond the rich limit of flammability. In fact, the correlation requires that the oxygen concentration in the outflow is uniform (or well-mixed), which is the case for fully developed (post flashover) fires. For under- 
ventilated fires, the expression (9) may result in an overestimation of the HRR due to the lower uniformity of oxygen concentration in the outflow. In the numerical simulation, when the value of GER is close to 3, the fire source inside the compartment is no longer sufficiently supplied with fresh air. The predicted GER value of 3 corresponds to the rich limit of flammability of wood fuel-air mixture beyond which fire exhaust occurs inside compartment with a significant reduction in HRR (cf. Fig.15). Indeed, the predicted critical GER value for fire exhaust is somewhat below to the Tewarson's data [37] primarily from the fire propagation apparatus. It is believed that the Tewarson's data may be not completely applicable to a compartment with an opening that is elevated above the floor. In fact, fire exhaust inside enclosure remains quite complex since it depends strongly on the temperature-dependent reaction kinetics. The EDC type is temperature independent combustion model, and chemical reaction takes place at a stoichiometric fuel-air mixture. So the predicted critical GER value of 3 is qualitatively promising as compared to the experimentally determined one [37].

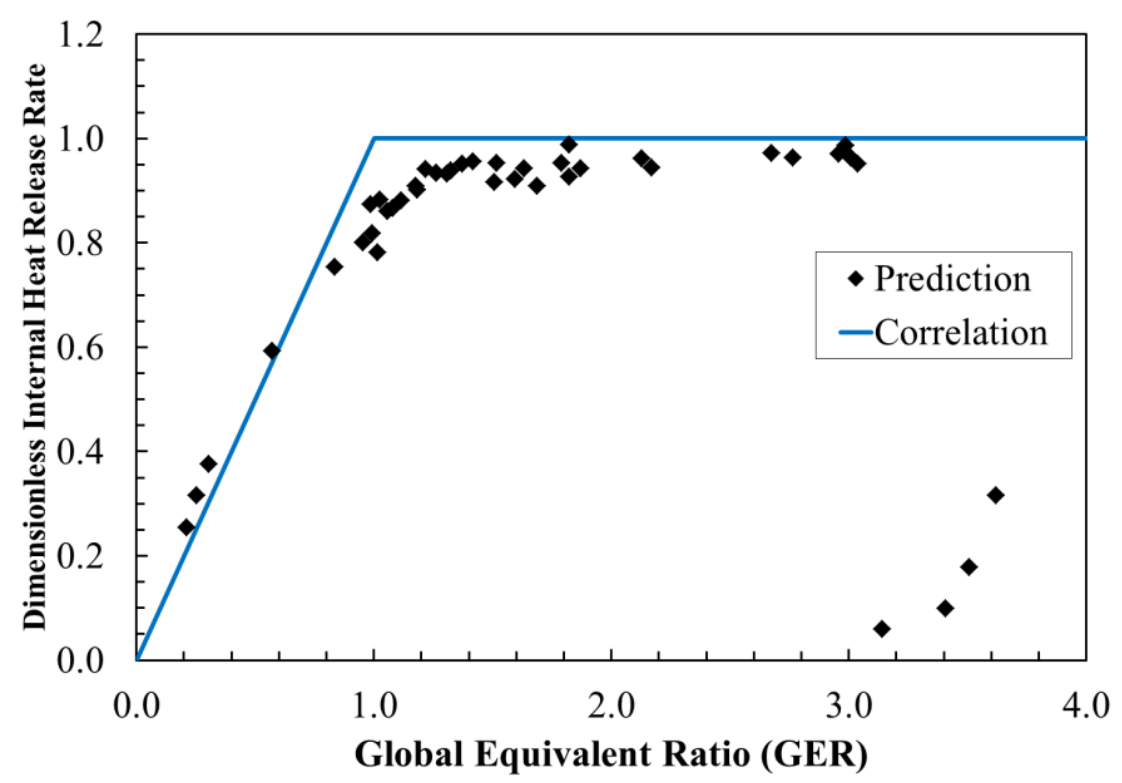

Figure 15. Evolution of the dimensionless internal HRR by combining the three parameters such as $\dot{Q}, \mathrm{~h}$ and w with a discrepancy below $5 \%$ between the prediction and correlation for GER below 3 .

As an illustration, Case 4 (cf. Tab.2) is chosen for understanding evolution of the compartment mean temperature and the internal heat release rate as a function of the normalized separation distance, D/w, varying from 1 to 4 . According to this numerical study, the fire behavior inside compartment with the seven scenarios (cf. Tab.2) is substantially identical to Case 4. The temperature inside the enclosure is spatially uniform (cf. Fig.14). As shown in Figure 16, the presence of the sidewalls positioned at the opening does not affect the mean temperature inside the compartment. This trend is similar to the experimentally observed one [1-2]. The façade fire ejecting behavior without sidewalls is closely related to the air entrainment from both front and side. With presence of the sidewalls adjacent directly to the opening, the fresh-air entrainment from side towards the compartment is fully constrained. Thus, the ventilation controlled internal HRR for the distance of $\mathrm{D} / \mathrm{w}=1$ is substantially lower than the one for the separation distance $(\mathrm{D} / \mathrm{w})$ beyond 1 . This induces an increase in the amount 
of combustible gases ejected from the opening, and consequently in flame height (cf. Fig.12). Whereas, the heat released inside the compartment varies slightly with a further increase of the sidewalls separation distance $(\mathrm{D} / \mathrm{w}>1.5)$. This suggests that the fresh air inflow rate from front and side is not affected once the sidewalls are far away from the opening, and the same ventilation-controlled fire regime inside the compartment is maintained.

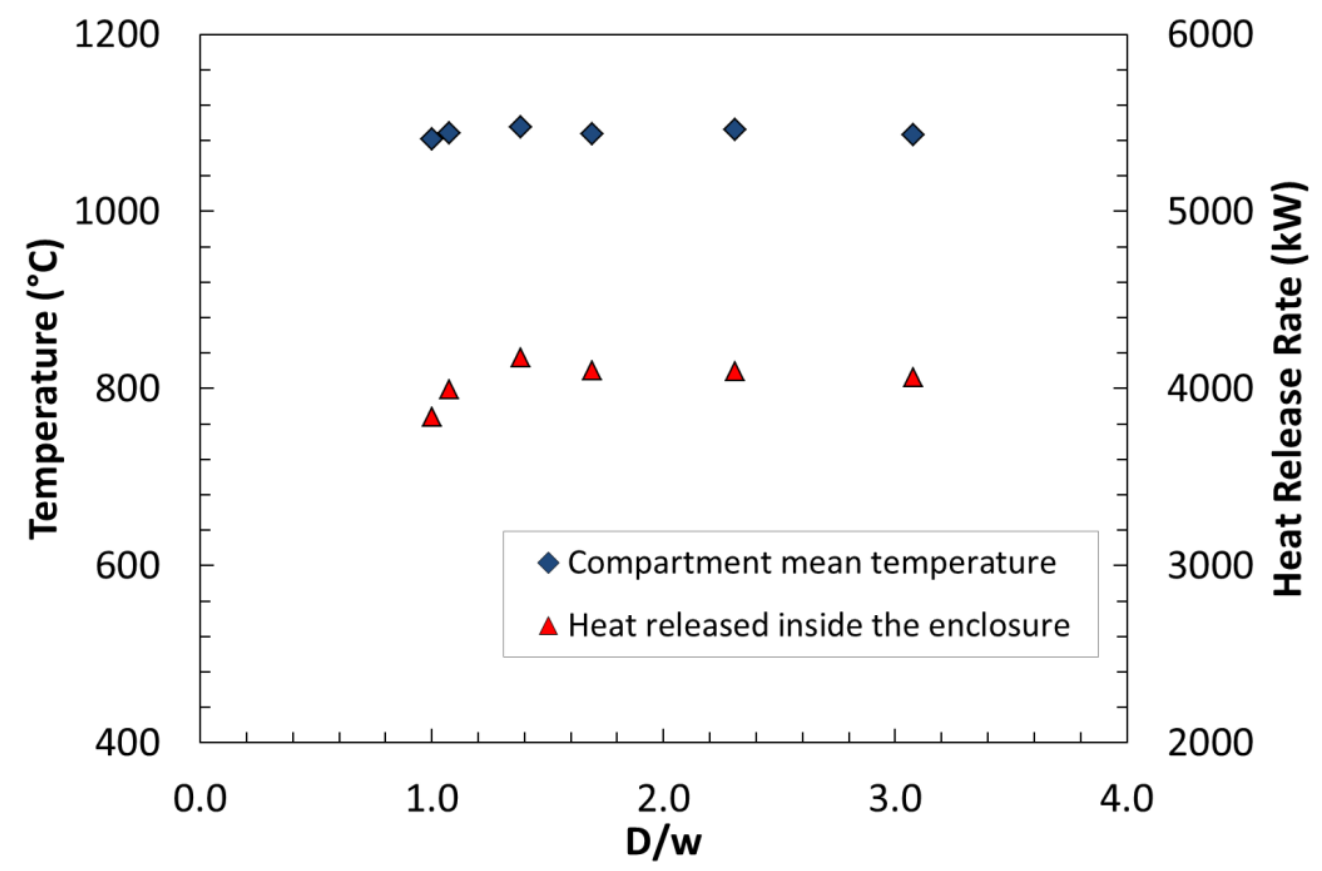

Figure 16. Evolution of the compartment mean temperature and heat release rate inside the enclosure as a function of the normalized separation distance (D/w) for Case 4

In fire plume, the majority of the radiation is derived from the visible part of the flame with a temperature higher than $500^{\circ} \mathrm{C}$, where soot particles are radiating heat $[27,39]$. The radiation heat flux is a function of both the gas temperature with the $\mathrm{T}^{4}$ dependence and chemical composition (soot, $\mathrm{CO}_{2}, \mathrm{H}_{2} \mathrm{O}$ ). Neither of which can be reliably calculated in a fullscale fire calculation because the flame sheet is not well-resolved on a relatively coarse numerical grid. The measured radiative heat flux is not available for a full-scale façade fire with sidewalls due to both the cost and difficulty in the measurement of heat flux. The numerical simulations appear useful to evaluate qualitatively the modes of heat transfer.

In FDS [22], soot production is derived solely from the fraction of the fuel mass that is converted into soot. Such soot yield approach does not incorporate the essential physical processes of soot inception, coagulation and surface growth in addition to the influences of turbulent fluctuations, temperature and fuel type [40, 41]. For the pine type of wood, the soot yield value of 0.015 is available [37, 39] only for well-ventilated fires. Therefore, sensitivity of the soot yield value on the radiative predictions at a given elevation of $5.5 \mathrm{~m}$ along the façade wall was first evaluated for a under-ventilated fire as Case 4. Two specific soot yield values of 0.01 and 0.04 were chosen to evaluate its sensitivity on the predicted radiative heat flux in Figure 17. For a given soot yield value, the oscillation behavior is attributed to the buoyancyinduced instability. Use of two soot-yield values induces the different transient peak values for the radiation heat flux via a radiative transfer equation. It is found that with multiplying the soot 
yield value by a factor of 4 , the radiation heat flux increases by a factor of $30 \%$ with a rise of the peak from 15 to $20 \mathrm{~kW} / \mathrm{m}^{2}$. Therefore, use of such soot yield approach may induce an uncertainty within $30 \%$ by taking into account the transition from well- to under-ventilated enclosure fire.

As an illustration, the effect of reducing the separation distance between sidewalls on the radiation heat flux to the façade surface at centerline is examined in Figure 18 for Case 4 using a soot yield value of 0.015 for wood. Evolution of the radiation flux along the flat façade $(\mathrm{D}=\infty)$ shows a similar trend to the Chotzoglou's finding [42] from a small-scale corridor-like enclosure. As expected, radiation energy absorbed by the façade wall depends mainly on the size of the fire and the soot loading. The peak of the heat flux from the external flame to the façade wall rises from 70 to $90 \mathrm{~kW} / \mathrm{m}^{2}$ with a reduction in the separation distance. Presence of the sidewalls adjacent closely to the opening $(\mathrm{D}=2.8 \mathrm{~m})$ clearly enhances the radiative heat transfer with the strongest heat flux close to the opening due to a large flame thickness there. In all the cases, it is ensured that if the façade assembly contains inflammable materials, the heat flux is high enough for inducing an ignition of façade fuel package exposed to the external flame near the opening. Particularly, a reduction in the distance between the sidewalls will significantly enhance the fire spreading rate and its size due to the increasing contribution by radiation. An experimental database on heat flux, owing to pyrolysis of an inflammable façade, over the full-scale façade with sidewalls constrains at the opening is needed for validation of the numerical tool.

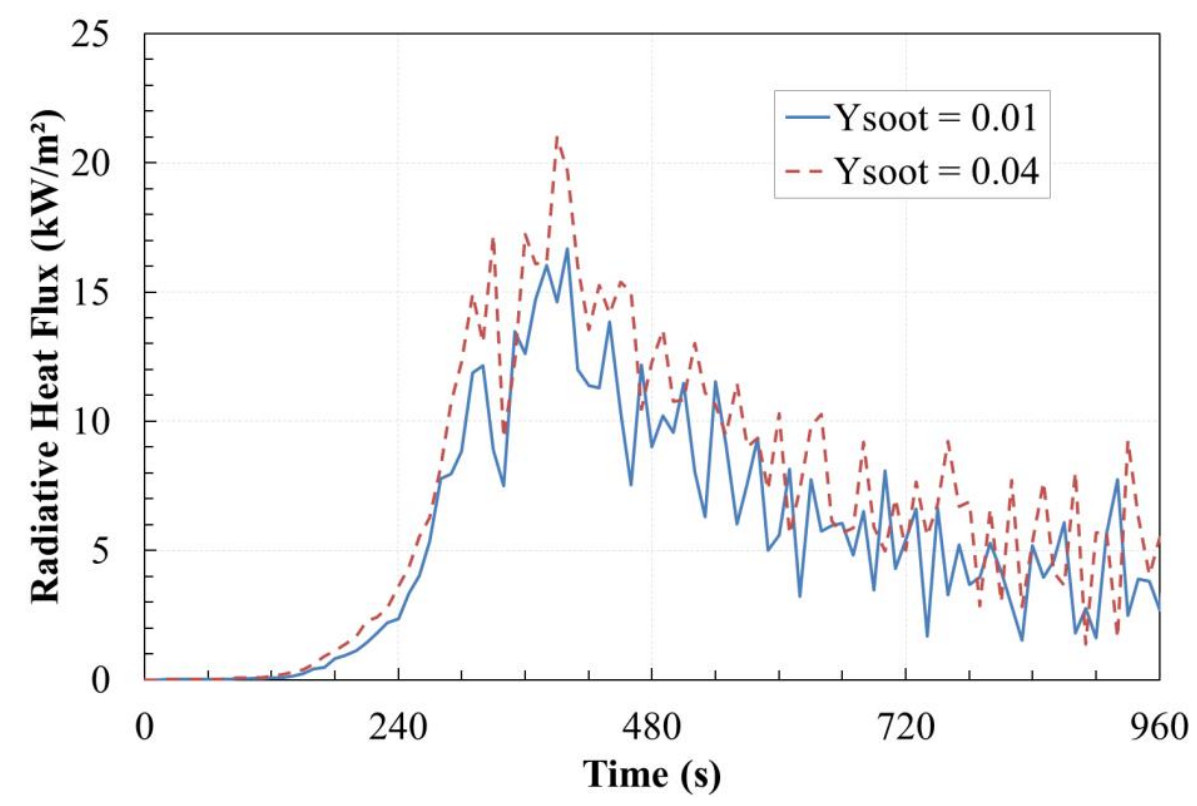

Figure 17. Comparison of the radiative heat flux over façade surface at a height of $5.5 \mathrm{~m}$ for Case 4 with a difference of $30 \%$ between the soot yield values of 0.01 and 0.04 


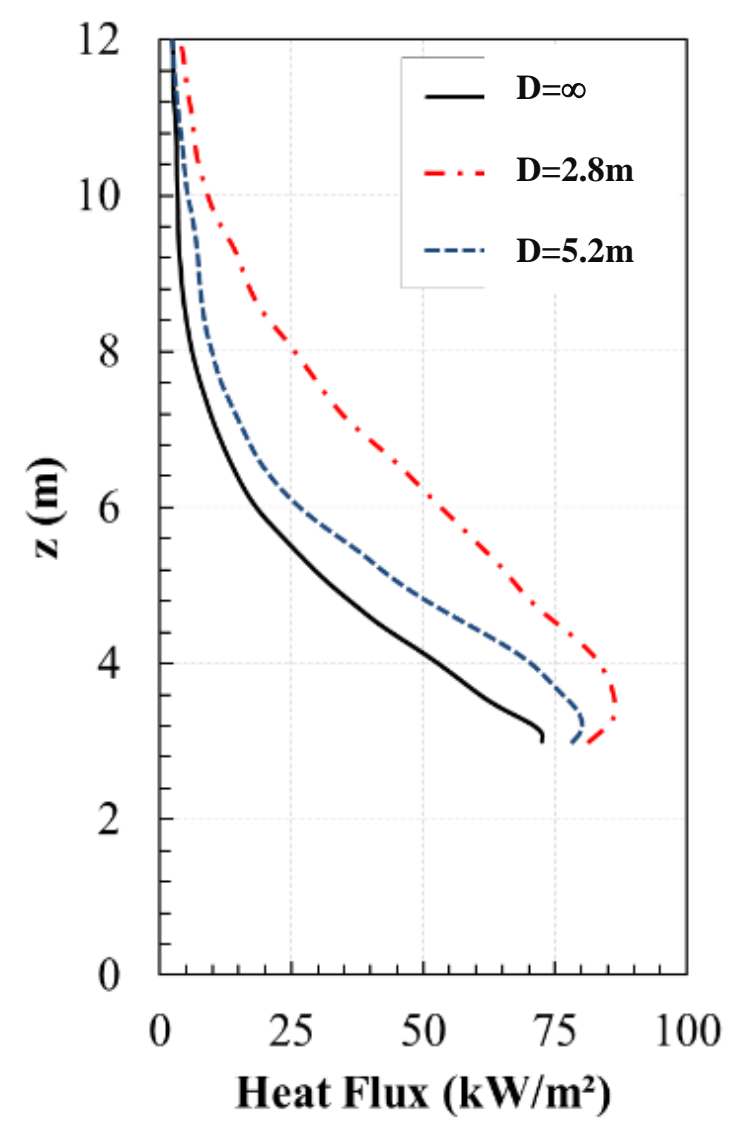

Figure 18. Evolution of heat flux along the façade centerline surface for three separation distances (D) within 30\% uncertainty for Case 4.

\section{CONCLUSIONS}

A series of numerical simulations was carried out for highlighting the flame ejecting behavior of full-scale enclosure fires with sidewalls constrains at the opening. The numerical model exhibits a more conservative behavior (over-prediction) in the intermittence zone of the spill flame which coincides with the periodic forward pulsations of flame due to the buoyant instability. Nevertheless, the numerical tool, is useful after detailed validation for full-scale fire to evaluate the correlations which are commonly derived from small-scale tests. The height of externally venting flame with sidewalls is much higher than that of flat façade due to a severe constrain of the air entrainment from side. The predicted spill flame height in full-scale is generally higher than that in small-scale from the correlation (14), owing probably to the turbulence development. The correlation (9) for the internal HRR might be used only in the case where the GER is lower than 3 corresponding to the rich limit of flammability of fuel-air mixture. The predicted dimensionless spill flame height as a function of sidewalls distance are shown to be well collapsed by the correlation (12). An inverse dependence of the flame height with the separation distance of sidewalls is predicted, following the correlation or experimental trend. Subsequently, the correlation (12) for dimensionless façade flame heights with sidewalls 
constrains can be used to enhance fire safety design methodologies for U-shape building façade in spite of scale effect.

\section{REFERENCE}

[1] K.H Lu, L.H Hu, F. Tang, M.A Delichatsios, X. Zhang and L.He (2013) Facade flame heights from enclosure fires with side wall at the opening, The 9th Asia-Oceania Symposium on Fire Science and Technology, Procedia Engineering, 62:202-210.

[2] K.H Lu, L.H Hu, F. Tang, L.H. He, X.C. Zhang and Z.W. Qiu (2014) Experimental investigation on window ejected facade flame heights with different constraint side wall lengths and global correlation, International Journal of Heat and Mass Transfer, 78 p.1724.

[3] F. Tang, L.H Hu, M. Delichatsios, K.H Lu and W. Zhu (2012) Experimental study on flame height and temperature profile of buoyant window spill plume from an under-ventilated compartment fire, International Journal of Heat and Mass Transfer, p. 93-101.

[4] B. Merci and K. Van Maele (2008) Numerical simulations of full-scale enclosure fires in a small compartment with natural roof ventilation, Fire Safety Journal, p. 495-511.

[5] W. Wegrzynski and G. Vigne (2017) Experimental and numerical evaluation of the influence of the soot yield on the visibility in smoke in CFD analysis, Fire Safety Journal, 91, 389-398.

[6] Hostikka, R. Kallada, U. Riaz, T. Sikanen (2017) Fire-induced pressure and smoke spreading in mechanically ventilated buildings with air-tight envelopes, Fire Safety Journal, 91, 380-388.

[7] T. Sikanen and S. Hostikka (2017) Predicting the heat release rates of liquid pool fires in mechanically ventilated compartments, Fire Safety J. 91, 266-275.

[8] X. Xing, J. Zhang and Y. Li (2013) A computational study on structural barrier to vertical spread of window spill plume along building exterior facade, Procedia Engineering 52, p. $475-482$.

[9] L. Cao and Y. Guo (2003) Numerical simulation of external fire spread through openings, International Journal on Engineering Performance-Based Fire Codes, Volume 5, Number 4, p.176-180.

[10] H. Xin, N. Zhaopeng and L. Shichang (2009) Large eddy simulation on effects of wall pier and overhanging eave in preventing vertical fire spread, Application of Structural Fire Engineering, p.125.

[11] M. Duny, D. Dhima, J.P. Garo and H.Y. Wang (2015) Numerical investigation on window ejected façade flames, Proceedings of International Fire Safety Symposium, p. 463-472.

[12] N.D Pope and C.G Bailey (2006) Quantitative comparison of FDS and parametric fire curves with post-flashover compartment fire test data, Fire Safety Journal, 41, p. 99-110. 
[13]B. Martinez (2013) Contribution to the study by numerical simulation of a fire plume coming out through a window on façade - Application to the comprehension of the wind influence on an eventually stack effect, Proceedings of $1^{\text {st }}$ International Seminar for Fire Safety of Facades, 03004.

[14] E. K. Asimakopoulou, D. I. Kolaitis and M. A. Founti (2017) Thermal characteristics of externally venting flames and their effect on the exposed façade surface, Fire Safety Journal, 91:451-460.

[15] C.L. Beyler (1986) Fire plumes and ceiling jets, Fire Safety Journal, 11:53-75.

[16] K. Himoto, T. Tsuchihashi, Y. tanaka (2009) Modeling thermal behaviors of window flame ejected from a fire compartment, Fire Safety Journal, 44:230-240.

[17] Lee, Y., Delichatsios, M. A., Silcock, G. (2008) Heat flux distribution and flame shapes on the inert façade, Fire Safety Science, 9:193-204.

[18] Tang F., Hu L.H., Qiu Z.W., Zhang X.C. and Lu K.H. (2015) Window ejected flame height and heat flux along façade with air entrainment constraint by a sloping facing wall, Fire Safety Journal, 71:248-256.

[19] M. Quinn, A. Nadjal, F, All and A. Abut-Tair (2013) Experimental and numerical investigation of localised fire on glazing façades having different orientations, Journal of Structual Fire Engineering, Vol.4, N³, p.153-164.

[20] Kaihua Lu, Longhua Hu, Michael Delichatsios, F. Tang, Z. Qiu and L. He (2014) Merging behavior of façade flames ejected from two windows of an under-ventilated compartment fire, Proceedings of the Combustion Institute.

[21] M. Li, Z. Gao, K, Li and J. Sun (2017) Wind effects on flame projection probability from a compartment with opposing openings, Fire Safety Journal, 91:414-421.

[22] K. Mcgrattan, R. Mcdermott, S. Hostikka and J. Floyd (2013) Fire Dynamics Simulator (Version 6), user's guide, NIST Special Publication.

[23] W. Zhang, N. Ryder, R.J. Roby and D. Carpenter (2001) Modeling of the combustion in compartment fires using Large Eddy Simulation Approach, In proceeding of the 2001 Fall Technical Meeting, Eastern States Section. Combustion Institute, Pittsburgh, Pennsylvania, December 27.

[24] J.Kruppa (1979) Comportement au feu des poteaux extérieurs en acier, Technical Report1.012-4, Centre Technique Industriel de la Construction Métallique.

[25] S. Desanghere (2006) Détermination des conditions d'échauffement de structure extérieure à un bâtiment en situation d'incendie. PhD Thesis, INSA of Rouen, France.

[26] X. Zhang, M. Yang, J. Wang, Y. He (2010) Effects of computational domain on numerical simulation of building fires, J. Fire Prot. Eng. 20:225-250.

[27] G. Kolb, J.L. Torero, J.M. Most and P. Joulain (1997) Cross flow effects on the flame height of an intermediate scale diffusion flame, Proceedings of the International Symposium on Fire and Technology, Seoul, Korea, 169-177.

[28] Wei Tang, D. Gorham (2017) An experimental study on the intermittent extension of flames in wind-driven fires, Fire Safety Journal 91:742-748. 
[29] Ning Ren, Yi Wang and A. Trouvé (2013) Large eddy simulation of vertical turbulent wall fires, The 9th Asia-Oceania Symposium on Fire Science and Technology, Procedia Engineering 62:443-452.

[30] H.Y. Wang, M. Coutin and J.M. Most (2002) Large-eddy-simulation of buoyancy-driven fire propagation behind a pyrolysis zone along a vertical wall, Fire Safety Journal 37, p.259-285.

[31] Nolan P.F., Brown D.J., Rothwell E. (1973) Gamme-radiographic study of wood combustion, 14th Symposium (Intl.) on Combustion, The Combustion Institute, Pittsburg.

[32] A. Kolbrecki (2015) Model of fire spread out on outer building surface, Bulletin of the polish academy of sciences, Vol. 63, No. 1.

[33] K. Kawagoe (1958) Fire Behaviour in Rooms, Report of the Building Research Institute, Ibaraki-ken, Japan, No.27.

[34] Coutin M, Most JM, Delichatsios MA, Delichatsios MM. (1999) Flame heights in wall fires : effects of width, confinement and pyrolysis length. Proceedings of the Sixth International Symposium on Fire Safety Science, Poitiers, France, p.729.

[35] G. Legros, P. Joulain, J.P. Vantelon, A. Fuentes, D. Bertheau, J.L. Torero (2006) Soot volume fraction measurements in a three-dimensional diffusion flame established in microgravity, Vol.178: 813-835, Combust. Sci. Technol.

[36] J. Lassus, L. Courty, J.P. Garo, E. Studer, P. Jourda and P. Aine (2014) Ventilation effects in confined and mechanically ventilated fires, International Journal of Thermal Sciences, p. 87-94.

[37] A. Tewarson (2002) Generation of Heat and Chemical Compounds in Fires. SFPE Third edition, p.3-82.

[38] Babrauskas, V. (2003) Ignition Handbook, Fire Science Publishers, Chapter 4, pp.41-140.

[39] D.J. Rasbash, D.D. Drysdale (1982) Fundamentals of smoke production, Fire Safety Journal, 5, 77-86.

[40] Moss, J.B., Stewart, C.D., Young, K.J. (1995) Modelling soot formation and burnout in a high temperature laminar diffusion flame burning under oxygen-enriched conditions, Combustion and Flame, 101, pp. 491-500.

[41] Lindstedt, P.R. (1994) Soot formation in Combustion, Springer-Verlag, p.417.

[42] K. Chotzoglou, E. Asimakopoulou, J.P. Zhang, M. Delichatsios (2018) Experimental investigation of externally venting flames geometric characteristics and impact on the façade of corridor-like enclosures, Journal of Physics: Conference Series, 1107(4), 042024. 